\title{
Chinese expert consensus on diagnosis and management of severe asthma
}

\author{
Jiangtao Lin ${ }^{*}$, Dong Yang ${ }^{2 *}$, Mao Huang ${ }^{3 *}$, Yongming Zhang ${ }^{1 *}$, Ping Chen ${ }^{4 *}$, Shaoxi Cai ${ }^{\text {* }}$, \\ Chuntao Liu ${ }^{6 *}$, Changgui $\mathrm{Wu}^{7 *}$, Kaisheng Yin ${ }^{3 *}$, Changzheng Wang ${ }^{8 *}$, Xin Zhou ${ }^{9 *}$, Nan Su ${ }^{1 *}$; on behalf \\ of Asthma Workgroup of Chinese Thoracic Society, Chinese Medical Association, and China Asthma \\ Alliance
}

\begin{abstract}
${ }^{1}$ Department of Respiratory and Critical Care Medicine, China-Japan Friendship Hospital, Beijing 100029, China; ${ }^{2}$ Department of Respiratory Medicine, Zhongshan Hospital, Fudan University, Shanghai 200032, China; ${ }^{3}$ Department of Respiratory Medicine, First Affiliated Hospital of Nanjing Medical University, Nanjing 210029, China; ${ }^{4}$ Department of Respiratory Medicine, General Hospital of Shenyang Military Region, Shenyang 110015, China; 5 Department of Respiratory Medicine, Nanfang Hospital of Southern Medical University, Guangzhou 510515, China; ${ }^{6}$ Department of Respiratory Medicine, West China Hospital of Sichuan University, Chengdu 610041, China; ${ }^{7}$ Department of Respiratory Medicine, Xijing Hospital of Fourth Military Medical University, Xi'an 710032, China; ${ }^{8}$ Department of Respiratory Medicine, Xinqiao Hospital of Third Military Medical University, Chongqing 400037, China; 'Department of Respiratory Medicine, First People’s Hospital, Shanghai Jiao Tong University, Shanghai 200080, China

Correspondence to: Prof. Jiangtao Lin, MD, PhD. Department of Respiratory and Critical Care Medicine, China-Japan Friendship Hospital, 2 Yinhuayuan Dong Lu, Chaoyang District, Beijing 100029, China. Email: jiangtao_1@263.net.
\end{abstract}

Submitted Jun 10, 2018. Accepted for publication Nov 25, 2018.

doi: $10.21037 /$ jtd.2018.11.135

View this article at: http://dx.doi.org/10.21037/jtd.2018.11.135

Bronchial asthma (referred to as "asthma" hereinafter in this consensus document) is a chronic inflammatory airway disease with well-accepted heterogeneity and complex pathophysiological processes (1). Severe asthma is recognized as a poorly controlled condition that seriously affects quality of life, accounts for massive use of medical resources, and imposes huge socioeconomic burdens, representing a primary cause of asthma-related disability and death in the patients (2-5). In this regard, improving the diagnosis and treatment of severe asthma should be of paramount importance towards better outcomes in overall control and prognosis, as well as lower medical costs (5).

Recently, China Asthma Alliance (CAA) in collaboration with the Chinese Medical Association Asthma Workgroup, released an updated version to the Chinese Expert Consensus on Diagnosis and Treatment of Difficult-to-Treat Asthma published 2010 elsewhere (6), based on in-depth discussions within a summoned panel of Chinese specialists, relevant international guidelines $(2,7,8)$ and focused articles about severe asthma appearing in the past few years. The updated consensus is desired to renew understandings on aspects about the definition, diagnosis, assessment, and management of severe asthma. This consensus document incorporates current opinions $(9,10)$ from within and outside the country, emphasizing the need for phenotyping and individualized treatment among severe asthma patients.

\section{Definition of severe asthma}

Definition of severe asthma has long been inconsistent worldwide or in China $(1,2,6-8)$ and therefore, terminology related to this condition ubiquitously included severe astbma, refractory asthma, difficult-to-control asthma, poorly controlled asthma, drug-resistant asthma, corticosteroid-insensitive asthma, corticosteroid-dependent and/or resistant astbma, brittle asthma, irreversible astbma, life-threatening asthma, and fatal astbma, which corresponds to Zhongzheng Xiaochuan, Zhongdu Xiaochuan, Nanzhi Xing Xiaochuan, Nan Kongzbi Xiaochuan, Wei Kongzhi Xiaochuan, Yaowu Dikang Xiaochuan, Fisu Bu Mingan Xiaochuan, Fisu Yilai/Dikang Xiaochuan, Cuixing Xiaochuan, Bukeni Xiaochuan, and Zhisi Xing Xiaochuan in Chinese literature.

* The authors are listed in the order by which their contribution section appears in this expert consensus document. 
This consensus document, in consistent with the 2014 European Respiratory Society/American Thoracic Society (ESR/ATS) guidelines (2), defines severe asthma as asthma that requires treatment with Step 4 or 5 medications as recommended by Global Initiative for Asthma (GINA) to maintain it under control, or that remains "uncontrolled" despite these therapies, during the previous year.

Severe asthma may include the following two scenarios: (I) the control of asthma remains well on the Step 4 medications but fails when de-escalating the treatment; (II) the control of asthma is not achieved with the Step 4 medications, rendering the use of Step 5 medications needed. In the first scenario, asthma is referred to as simple severe asthma; in the second, as severe refractory asthma.

Patients who fulfilled with the criteria of severe asthma may face high risks in the future, including those related to the condition per se (asthma exacerbation and impaired lung function) or associated with adverse drug reactions (10).

\section{Epidemiology and disease burden}

There is no clear epidemiological data on the incidence of severe asthma in adults and children. The 2000 ATS proceedings of the ATS workshop on refractory asthma mentioned that refractory asthma accounts for less than $5 \%$ of all asthma patients (7), while the 2014 ERS/ATS guidelines on definition, evaluation and treatment of severe asthma showed that severe asthma accounts for nearly $5 \%$ to $10 \%$ of asthma patients (2). According to the China Asthma and Risk Factors Epidemiologic Survey (CARE), asthma affects 1.24\% of Chinese adolescents (aged $\geq 14$ years) and adults; among them, $5.99 \%$ have severe asthma $(11,12)$.

The frequency of hospital or emergency room visits by severe asthma patients has been distinctly increasing, leading to massive use of health resources for the diagnosis and treatment. Annually, the direct treatment cost for severe asthma per capita in the United States is 14,212 USD (13); with regard to Europe, 2,635 Euros in Spain (14), 2,912 to 4,217 GBP in the UK (15); in South Korea, 2,214 USD (16). According to the China Asthma Research Network, hospital stays following an acute exacerbation of asthma were responsible for a direct treatment cost of as high as 11,603 Yuan RMB ( 1,730 USD) per patient per episode during 2013-2014 (17).

\section{Pathology and pathophysiology}

\section{Distinct heterogeneity in airway inflammation}

Inflammatory cells and mediators play important roles in the development and progression of severe asthma. Based on findings of induced sputum, bronchial mucosa biopsy and bronchoalveolar lavage, the airway inflammation in severe asthma may be eosinophilic, neutrophilic, mixedgranulocytic, or paucigranulocytic. These inflammatory endotypes are related to varying characteristics by anatomical structure, physiology and clinical presentation (18-20). Compared with mild to moderate asthma patients, those with severe asthma show more significantly elevated counts of eosinophils and neutrophils in the induced sputum (21), and higher-level expression of Th2 cytokines, such as IL-4, IL-5 and IL-13 (22-24). Among these cytokines, IL-4 may promote the differentiation of Th0 cells into Th2 cells, and the production of $\operatorname{IgE}$ by B lymphocytes; IL-5 is a critical cytokine involved in the maturation and activation of eosinophils; IL-13 not only induces IgE production and promotes eosinophil migration into the airways, but also causes airway hyperresponsiveness by acting on airway smooth muscle (ASM) cells. Infiltration of mast cells in the ASM represents one of the major pathological features in severe asthma $(25,26)$, which may be importantly responsible for the difficulty in asthma control and airway hyperresponsiveness (Figure 1). In certain severe asthmatics, increased infiltration of neutrophils in the airway can been seen (27). The airway neutrophilic inflammation may result from modulation by Th17 cells. The latter could promote production of a few cytokines such as IL-17, IL-22 and IL-6, and thereby have a certain role in corticosteroid-resistant asthma. Not only so, by inhibiting the apoptosis of fibrocytes and epithelial cells, they also aggravate airway remodeling $(28,29)$. Up-regulation of matrix metalloproteinase-9 (MMP-9) and transforming growth factor-beta (TGF-beta) concomitant with activation of neutrophils also adds to deterioration of the airway remodeling.

\section{Worse severity of airway remodeling}

Airway remodeling refers to the structural aberration of the airway as a consequence of repeated cycles of airway wall damages and repairs, and covers a cluster of pathological features including epithelial injury, goblet cell and mucous gland hyperplasia, mucinous metaplasia, subepithelial fibrosis, fibroblast activation and proliferation, thickened basement membrane, deposition of extracellular matrix (ECM) proteins, smooth muscle proliferation/hypertrophy, and angiogenesis. Airway structural cells (such as epithelial cells and smooth muscle cells) play an important role 


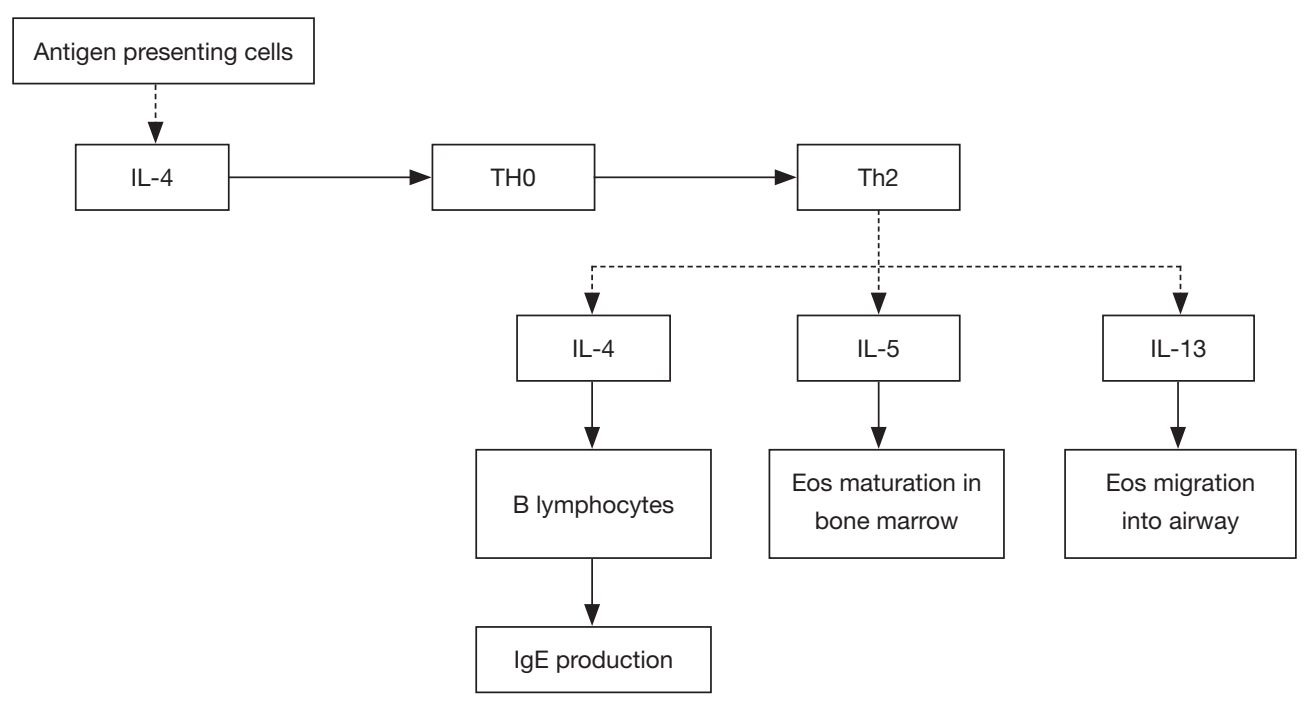

Figure 1 Relationship between T-helper cells differentiation and airway inflammation. IL, interleukin; Th, T helper cells; IgE, immunoglobulin E; Eos, eosinophils.

in the airway remodeling of severe asthma. They may be involved in the airway inflammation and remodeling by releasing various cytokines, chemokines and growth factors [such as epidermal growth factor (EGF), TGF-beta, keratinocyte growth factor, fibroblast growth factor (FGF), and vascular endothelial growth factor (VEGF)], and thereby cause persistent airflow limitation and worsened airway hyperresponsiveness. Compared with mild-tomoderate asthma patients, those with severe asthma may have earlier and more severe airway remodeling, remarkable thickening of the airway epithelial and smooth muscle layers $(30,31)$, and significantly higher number of peripheral blood fibroblasts that can differentiate into myofibroblasts $(32,33)$. Airway remodeling leads to lower airway elasticity, persistent or irreversible airflow limitation, progressive lung function decline, long-lasting airway hyperresponsiveness, and more severe symptoms, thus rendering asthma difficult to control (Figure 2).

\section{Connection with genetic factors}

Given that both genetic and environmental factors participate in the development and progression of asthma, genetic susceptibility is also found in severe asthma patients. Genome-wide association analysis offers an important approach in identifying and validating gene mutations and gene polymorphisms that confer susceptibility to severe asthma $(34,35)$. Understanding the biofunctional characteristics of these mutated genes may facilitate discovery of biological targets and novel therapeutic agents for different asthma phenotypes. Single nucleotide polymorphisms (SNPs) of IL-4 receptor alpha relate with persistent airway inflammation, acute exacerbation of severe asthma and submucosal mast cell infiltration (36). Mutations of IL-6 receptor are linked to lowered lung function and asthma severity (37). Development of severe or refractory asthma may be mechanistically underlined by pharmacogenetics which is associated with altered or attenuated response to asthma treatment in patients. For example, the patients harboring homozygous Gly16 SNP of beta-2 receptor show significant desensitization to bronchodilators $(38,39)$; corticotropin releasing hormone receptor 1 (CRHR1) polymorphisms are associated with resistance to corticosteroids (40). Moreover, modifications in non-coding DNA regions (such as DNA methylation or structural changes of chromosomal histones) and certain microRNAs (miRNAs) may also relate with the development of severe asthma, rendering further research warranted (41).

\section{Lowered responsiveness to glucocorticoids}

Severe asthma commonly manifests reduced glucocorticoid responsiveness, that is, no evident improvements in clinical symptoms or significant reduction of eosinophils in peripheral blood or sputum after treatment with 


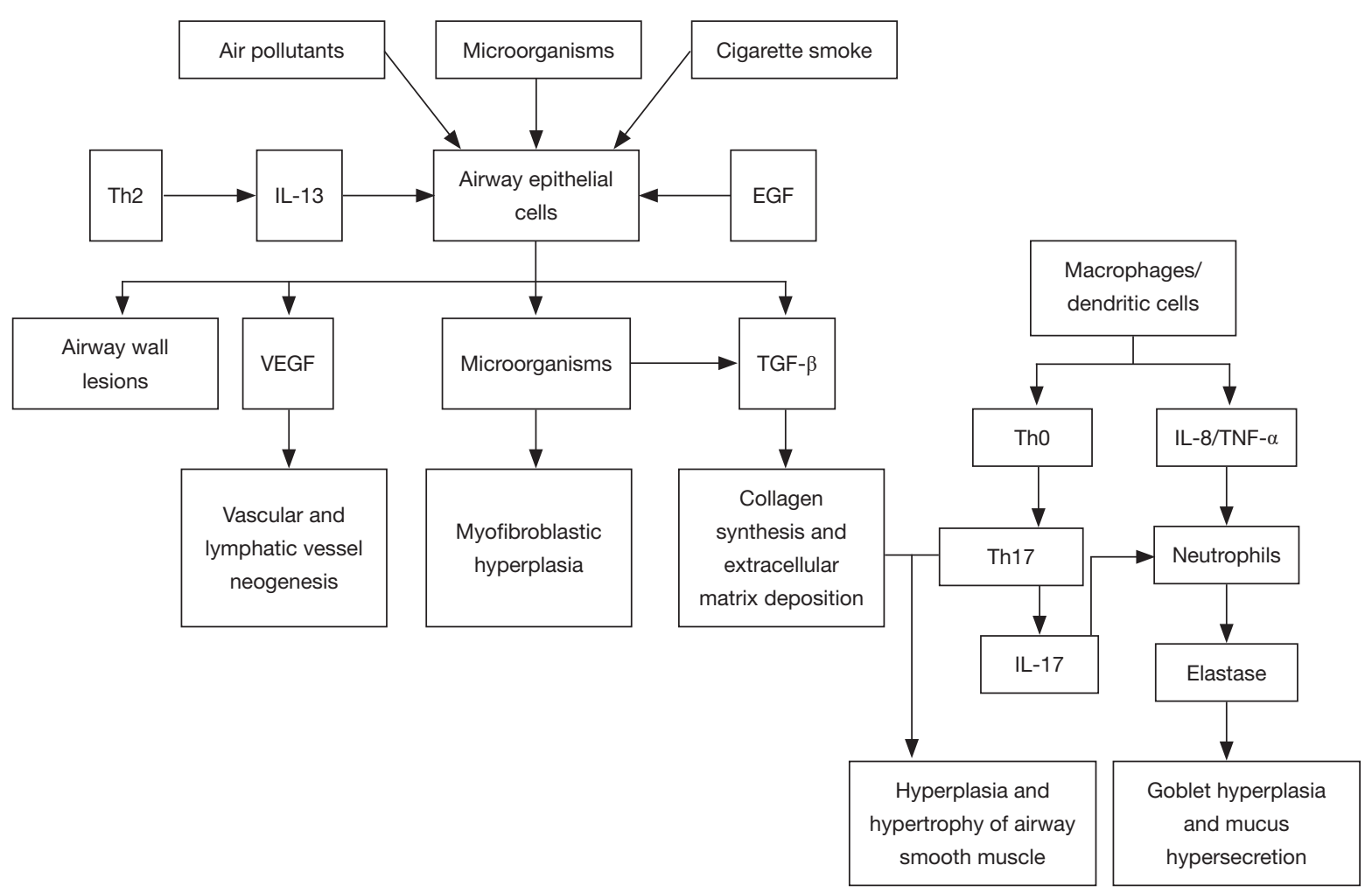

Figure 2 Schematic diagram of mechanism underlying airway remodeling. Th, T helper cells; IL, interleukin; EGF, epidermal growth factor; VEGF, vascular endothelial growth factor; TNF, tumor necrosis factor.

glucocorticoids. Due to the presence of gene polymorphism, mutated-type glucocorticoid receptors (GR) exhibit lower binding affinity to their ligands (42). The beta isoform of GR (GR-beta) may competitively inhibit the alpha isoform (GR-alpha) from exerting biological activity and block the nuclear translocation of GR-alpha directly or by affecting its transcription factor pathway $(43,44)$. Increased GR-beta expression may lead to lower glucocorticoid sensitivity. Oxidative stress induced by cigarette smoking and several other factors may cause a reduction in histone deacetylase activity $(45,46)$. This can be followed by activation of the p38 mitogen-activated protein kinase (p38-MAPK) pathway via cytokines like IL-4 and IL-13, which in turn phosphorylates GR and decreases its affinity with ligands, hence occurrence of corticosteroid resistance (47). Therefore, suppression of p38-MAPK activity favors the improvement of glucocorticoid sensitivity (48). Among obese asthmatics, lowered responsiveness to glucocorticoids could also be attributed to inhibition of MAPK phosphatase-1 (49). Furthermore, blockage of GR by the pro-inflammatory transcription factor nuclear factor (NF)- $\mathrm{kB}$ and impairment of the Toll- like receptor signaling pathway are also believed to be connected with reduced glucocorticoid responsiveness in patients with severe asthma (50). Figure 3 illustrates major mechanisms underlying the lowered glucocorticoid responsiveness.

\section{Factors affecting asthma control}

Asthma control may be affected by a number of factors, including patient adherence, environmental factors, medications, and comorbidities.

\section{Poor patient adberence}

Poor patient adherence to recommended treatments is one of the most important and common factors affecting asthma control. The reasons include (51): (I) refusing inhaled corticosteroids (ICS) therapy for the concern about potential adverse effects from steroids; (II) incapability to use the inhalation device properly; (III) failure to complete patientinitiated monitoring and evaluation of the condition in a proper and objective manner, such that self-tapering of doses 


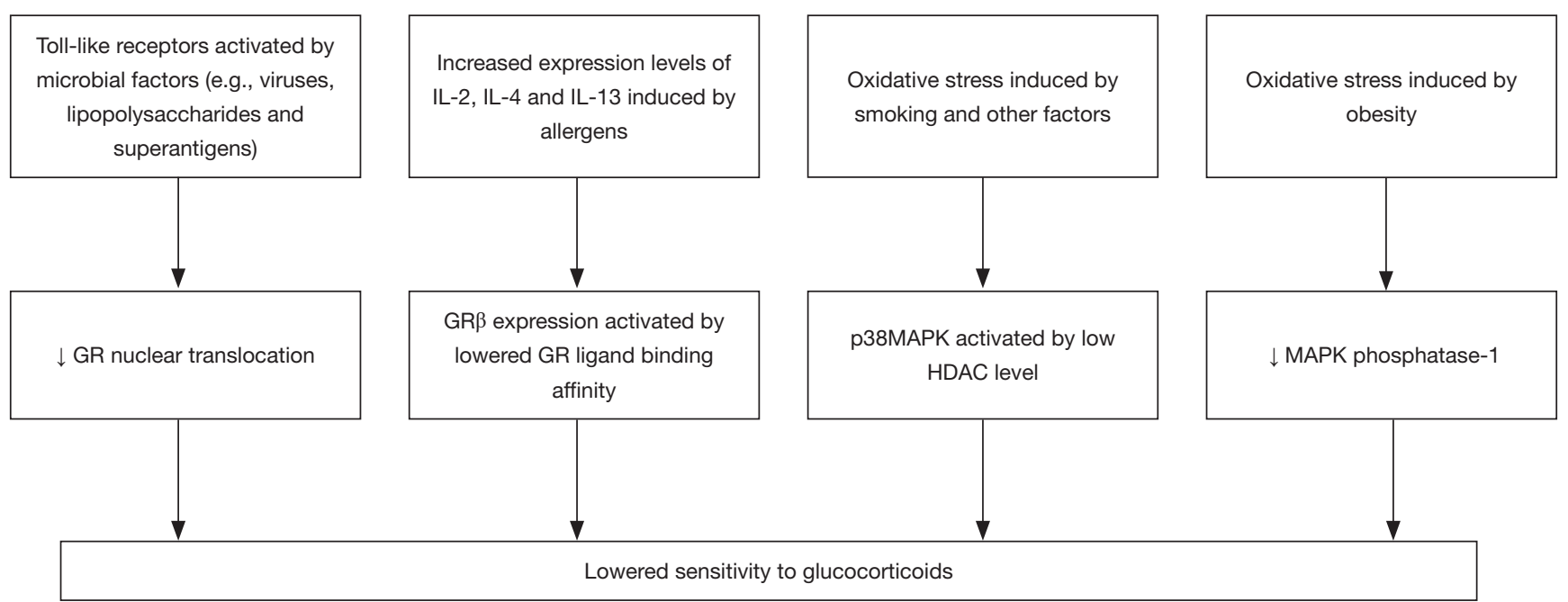

Figure 3 Mechanism underlying lowered sensitivity to glucocorticoids. IL, interleukin; GR, glucocorticoid receptor; HDAC, histone deacetylase; MAPK, mitogen-activated protein kinase.

or discontinuation of medications is arbitrarily decided when symptoms appear to improve; (IV) missing scheduled followup visits; and (V) using "folklore remedies" that claim to "cure" asthma, without discussing with the physician.

\section{Environmental factors}

Environmental factors in this setting mainly include allergens, tobacco smoke, air pollution, and occupational exposure. Asthma is difficult to control with lingering effects of environmental factors.

\section{Common allergens}

(I) Indoor and outdoor inhalant allergens: such as dust mites, molds, pollens (52), cockroaches, animal dander and secretions, silk and perfumes; (II) food allergens: such as hen eggs, dairy products, meats, soybean products, seafood, fruits, and nuts; and (III) contact allergens: such as cosmetics, hair dyes, and paints.

\section{Tobacco smoke}

Smoking during pregnancy and active or passive smoking during childhood can increase the incidence of asthma. Cigarette smoking is not only a trigger for asthma, but also an important cause of severe cases. It also adds to the difficulty for asthma control, and alters the inflammatory process in these patients. Of all emergency visits due to asthma exacerbation, nearly $35 \%$ of the patients have a history of smoking. Compared with non-smoking patients, active- or passive-smoking asthma patients may experience more severe symptoms, more episodes of symptom onsets, and faster decline in lung function. Smoking also leads to treatment resistance. Smokers showed lower response or resistance to inhaled or oral corticosteroids, and disrupted theophyllines metabolism by a $50 \%$ reduction in half-life of the drug, compared with non-smoking asthmatics. Passive smoking in adults and children is associated with poor efficacy of asthma treatments. Smoking cessation helps to control the symptoms and reduce acute exacerbations (53).

\section{Air pollution}

Atmospheric particulate matter of less than 2.5 micrometers in diameter (PM2.5), nitrogen oxides, nitrogen dioxide $\left(\mathrm{NO}_{2}\right)$, ozone, sulfur dioxide $\left(\mathrm{SO}_{2}\right)$, carbon dioxide $\left(\mathrm{CO}_{2}\right)$, acidic aerosols, formaldehyde, fuel fumes, paints, chemicals (such as volatile organic compounds and chlorine), and biological contaminants (such as endotoxins), when inhaled into the airways, may trigger or aggravate asthma through oxidative stress injury, inflammatory pathways, abnormal immune responses, and hyper-sensitivity to allergens. Paralleled with increasing air pollution, asthma appears to become more symptomatically severe, and is associated with more emergency visits and hospital admissions. A growing body of evidences suggests that severe asthma is closely related to air pollution (54).

\section{Occupational exposure}

As many as 300 occupational sensitizers have been reported. 
Table 1 Comorbidities in severe asthma

- Upper respiratory infections

- Rhinosinusitis/nasal polyps

- Sociopsychological factors: personality characteristics, perception of symptoms, anxiety, depression

- Vocal cord dysfunction

- Obesity

- Obstructive sleep apnea-hypopnea syndrome

- Endocrine considerations: premenstrual, intra-menstrual and menopausal factors, thyroid disorders

- Gastroesophageal reflux disease

At workplace, inhalation of dusts or gases containing animal and plant proteins, organic and inorganic chemicals (e.g., phthalic anhydride, toluene diisocyanate) may induce asthma through allergic (e.g., anhydrides or cereals) or nonallergic (e.g., isocyanates) pathogenesis (55). The everdeveloping industrialization is expected to correlate with a rising trend in the incidence of occupational asthma. Asthma is work-related in $9 \%$ to $15 \%$ of adults, among which, occupational exposure makes the asthma difficult to control (56). Avoidance of occupational exposure should therefore become the most important measure for prevention in these settings.

\section{Medications}

Asthma can be induced or aggravated by certain medications. To date, several hundreds of medications have been found to potentially cause asthma (57). These include the prostaglandin synthesis-inhibiting non-steroidal anti-inflammatory drugs (NSAIDs) (e.g., aspirin), beta-blockers, and angiotensin-converting enzyme inhibitors (ACEIs). The underlying mechanisms are categorized into two scenarios, drug allergies and drug reactions. Herein, drug allergy refers to intolerance or allergic reaction in a patient to certain medicines (e.g., aspirin, penicillin, sulfites, tartrates, food additives). Allergy to aspirin is seen in $2 \%$ to $25 \%$ of adult patients with asthma. Drug reaction refers to induction of asthma symptoms as a result of pharmacological actions of certain medicines (e.g., NSAIDs, beta-blockers, ACEIs).

\section{Comorbidities}

A number of comorbidities may interfere with asthma control. Table 1 is a list of such conditions commonly seen in severe asthma.

\section{Upper respiratory infection (URI)}

Respiratory viral infections are linked to onset and exacerbation of asthma (58-61). Among these, respiratory syncytial virus (RSV) is the most major risk factor for wheezing in babies and young children, accounting for nearly $70 \%$ of the cases, followed by rhinovirus, adenovirus, human metapneumovirus, and bocavirus. RSV infection is also associated with refractory asthma. In adults, infections with aspergillus, mycoplasma pneumoniae, and chlamydia may also play a role in asthma.

\section{Rhinosinusitis and nasal polyps}

Rhinosinusitis and nasal polyps are commonly seen in severe asthma. $75 \%$ to $80 \%$ of all asthma patients $(62,63)$, or $54 \%$ of patients with severe asthma (late-onset asthma in particular) (64), are comorbid with rhinosinusitis/ nasal polyps. Chronic rhinosinusitis with nasal polyps (CRSwNP) as a comorbidity further complicates asthma control, compared to chronic rhinosinusitis without nasal polyps (CRSsNP) (65). Asthma patients with nasal polyps usually report more acute exacerbations or greater need for hospital admission. In Belgium and China, studies showed that compared to asthma-CRSsNP patients, those with asthma-CRSwNP have significantly more severe eosinophilic inflammation, and higher levels of eosinophil cationic protein (ECP), and myeloperoxidase (MPO). In severe asthma patients who have rhinitis and Th2-biased eosinophilic polyps, serum staphylococcal enterotoxins have been shown to aggravate eosinophilic inflammations, increase $\operatorname{IgE}$ formation and its titer (66). The severity of rhinosinusitis relates to airway inflammation and lung 
dysfunction in asthma, which is possibly underlain by the following mechanisms: (I) nasal mediator release: due to similarity in inflammation between the upper and lower airways, inflammatory cells from nasal exudates may reach the lungs through systemic circulation, where they exert certain biological effects and cause airway hyperresponsiveness; (II) nasobronchial reflex: inflammatory stimulation of rhinosinal mucosa may be passed on via the parasympathetic nasobronchial reflex arc, and ultimately, through "neurally mediated amplification", causes remote bronchospasm; (III) direct effects of postnasal drip: the inflammatory products of the nasal mucosa drain directly into the lower airway through the oropharynx, resulting in constriction or worsened inflammation of bronchial smooth muscles, which in turn elicits onset of asthma or adds to inflammation and obstruction of the airways; and (IV) impaired mucociliary clearance function: inflammation in upper and lower airways exposes the M-cholinergic nerve receptors found on epithelial cells. Treatment of rhinitis, sinusitis, and nasal polyps helps improve asthma control, especially in patients with severe asthma necessitating use of systemic corticosteroids.

\section{Sociopsychological factors}

A survey in the UK showed that the frequency and severity of asthma symptoms are relatively higher among people with a low socioeconomic status. Another study that investigated the prevalence of allergic asthma in the US found that hospital-admission and mortality rates due to asthma are higher in patients with a lower income. Asthma can be a psychosomatic illness influenced by an interplay among somatic, psychic and social factors. Excessive mental stress or pressure during pregnancy may result in higher incidence of asthma in off-springs (67). Intense mental irritation, anxiety, fear, anger and excitement, all can trigger and aggravate asthma. Such effect is most predominant with anxiety, followed by anger, depression, fear, and excitement. Comorbidity with anxiety and depression was noted in $25 \%$ to $49 \%$ of adult patients with severe asthma. Negative emotions, such as anxiety, depression and resentment, may promote secretion of histamines that may cause or aggravate asthma. While mental factors may elicit asthma, the latter can also incur negative emotions, thereby forming a vicious cycle that hinders asthma control (68). Studies using Minnesota multiphasic personality inventory (MMPI) have shown that individuals with significant mental disorders are more likely to have severe asthma. This subset of patients usually shared certain characteristic psychology in common, such as lack of confidence in overcoming their condition, strong feelings of helplessness, and even worse, desperate denial of the disease and rejection of others' assistance. These mental problems adversely affect the severity, progression and treatment outcomes of asthma; not only so, they also interfere with the patient quality of life, mental well-beings, personality, family relationships, and social activities. Obviously, correction of these problems is important for prevention of asthma attacks in the patients.

\section{Vocal cord dysfunction (VCD)}

VCD is a non-organic dysfunction in which the paradoxical adduction of vocal cords and hence narrowing of the glottis during inspiration causes airflow obstruction at the throat level. VCD is manifested by symptoms of extra-thoracic airway obstruction, such as recurrent dyspnea, wheezing, cough, shortness of breath, and chest tightness. Typically, VCD is seen among teenagers, and in whom, frequently diagnosed with persistent asthma and treated with high-doses of ICS, systemic corticosteroids, and bronchodilators (69). Concomitant sinusitis or gastroesophageal reflux disease (GERD) can aggravate VCD. When comorbid with asthma (especially with severe asthma), VCD may add to the complexity of asthma diagnosis and disease severity. In VCD patients, but not asthmatics, the inspiratory flow-volume curve appears flat or truncated.

\section{Obesity}

This is a major risk factor for asthma in children and adults, leading to lowered quality of life, greater body mass index (BMI), more asthma-related missed school days, longer hospital stay, increased emergency visits and limitations in activities. Due to prolonged intensive care unit or hospital stay, obese children with asthma usually receive higher doses of oxygen therapy, salbutamol, and intravenous corticosteroids, and also suffer more serious illness, compared with normal-weighted asthmatic children $(70,71)$. Severe asthma seems to be increasingly serious in parallel with greater BMI-about $70 \%$ of patients with severe asthma are overweight or obese. Asthma in the obese is typically irresponsive to inhaled glucocorticoids, and frequently presents a unique clinical phenotype: comorbidity with GERD, increased proton pump inhibitors use, higher T-scores of bone mineral density, reduced forced vital capacity (FVC), lower serum $\operatorname{IgE}$ levels inversely correlated with increasing BMI, and often with a history of eczema rather than nasal polyps. The following mechanisms are believed to underlie the impacts of obesity on asthma: 
(I) mechanical factors: in these obese patients, the alterations in respiratory mechanics caused by excessive fat deposition in the diaphragm, chest wall, and abdominal cavity result in lower compliance of the lungs and thoracic cage, upward shifting of the diaphragm, hence reductions in lung volume, functional residual capacity, forced expiratory volume in one second $\left(\mathrm{FEV}_{1}\right)$ and FVC. In turn, these lead to rapid shallow breathing and impaired central respiratory drive. The severity of restrictive ventilation dysfunction is positively correlated with obesity. Along with higher $\mathrm{BMI}$, the $\mathrm{FEV}_{1} / \mathrm{FEC}$ ratio gradually falls (decreasing by $>1 \%$ for every 5 -unit increment in BMI); (II) up-regulated inflammation in the airways: obesity is a systemic (as well as airway) inflammatory condition featured by massive involvement of pro-inflammatory cytokines and adipokines (leptin, adiponectin, resistin, IL6 , tumor necrosis factor-alpha and C-reactive proteins); and (III) comorbid diseases: compared with the non-obese, obese patients are more likely to have sleep-disordered breathing, GERD, and dyslipidemia (72).

\section{Obstructive sleep apnea hypoventilation syndrome (OSAHS)}

Compared with the general population, OSHAS is more prevalent as comorbidity in asthma patients, and in whom, also called alternative overlap syndrome. OSAHS causes recurrent exacerbation of asthma and therefore makes asthma control difficult (73-75). Aggravation of asthma by OSAHS may be underlain by several aspects: (I) nerve reflex: apnea-induced stimulation of neural receptors at the larynx and glottis may give rise to reflexive bronchoconstriction. Consequently, upper airway narrowing results in increased airway resistance, negative chest pressure, and high vagal tone, thereby causing airway hyperresponsiveness or wheezing; (II) airway inflammation: in OSAHS, the upper airway and systemic inflammation can involve the lower airway, leading to asthma and even the risk for onsets of fatal asthma; (III) OSAHS is frequently accompanied by GERD. In these patients, the increased negative chest pressure and intra-abdominal pressure, hence a great difference between chest and abdomen pressures, facilitate reflux of gastric acids. The latter can subsequently lead to development of laryngitis and laryngeal edema that add to upper airway obstruction; (IV) airway remodeling: nocturnal intermittent hypoxia in OSAHS patients may cause up-regulated expression of hypoxia inducible factor (HIF) which is shown to relate to airway remodeling; and (V) obesity: the high levels of leptin found in OSAHS patients may lead to airway hyperresponsiveness, and moreover, cause obesity via insulin resistance and lipid metabolism disorders. All of these make asthma difficult to control.

\section{Endocrine considerations}

Asthma can become exacerbated or worsened around menstruation, at menarche, in menopause, or with concomitant thyroid disorders. Perimenstrual asthma (PMA) is seen among nearly $40 \%$ of female asthmatics of childbearing age (76), usually presenting with difficult-tocontrol symptoms that may trigger life-threatening asthma. It has been currently believed that asthma plays important roles in development of allergic inflammation as an immune response, and in influencing the neuroendocrine functions in the body (especially of the hypothalamus), while neuroendocrine functions in turn exert significant regulatory actions in immune responses. Patients with PMA frequently have concomitant allergy to aspirin and a low predicted $\mathrm{FVC} \%$ value, suggesting the pivotal role of prostaglandins in PMA. In these patients, dramatically lowered levels of estrogen and progesterone can be noted to last for 2 to 7 days around the menstruation, which could trigger inflammations and thereby cause aggravation of asthma symptoms (77). Severe asthma in females can be comorbid with hyperthyroidism crisis. Altered thyroid function is associated with the risk for asthma. Thyroid hormone receptor gene polymorphisms have been shown to influence patient response to bronchodilators, suggesting that at least to a certain extent, thyroid hormones may intersect with mechanisms of airway constriction in asthma (78).

\section{GERD}

GERD refers to a series of clinical syndromes elicited by frequent reflux of gastric contents via the lower esophageal sphincter into the esophagus. About $60 \%$ to $80 \%$ of patients with asthma have concomitant GERD $(62,63)$. Studies showed that the proportion of GERD (34\% to $89 \%$ ) is significantly higher in asthma (severe asthma in particular) than that in the general population (5\% to $10 \%)$. Probable mechanisms that underlie asthma aggravation by GERD $(79,80)$ include: (I) patients with GERD-comorbid asthma often suffer autonomic dysfunction with vagal overactivity, which leads to frequent, transient relaxation of the hypotonic lower esophageal sphincter. The reflux of acidic gastric contents then stimulate the mucosal receptors at middle and lower parts of the esophagus, resulting in contraction of the bronchial smooth muscle through vagal reflex; (II) aspiration of regurgitated gastric contents into the airways can increase the bronchial hyperresponsiveness 
to other stimulants such as acetylcholine; (III) microaspirations of gastric contents may cause airway acidification and subsequently cause airway contraction by direct stimulation of vagal nerve receptors, resulting in higher airway resistance and significant airway hyperresponsiveness; and (IV) the acidic gastric contents may activate local axonal reflexes, which promotes proinflammatory mediators (e.g., substance $\mathrm{P}$ ) release from bronchial mucosa and eventually results in airway edema. Patients with typical GERD-like symptoms, e.g., burning retrosternal sensation, recurrent cough, or coughing after acidic foods/drinks consumption or overeating should be evaluated for GERD.

\section{Clinical phenotypes}

Exact definitions and consistent criteria for the concept of asthma phenotypes remain lacking. Despite this, given the differences in clinical characteristics and responsiveness to medications, clinical phenotyping of asthma favors individualized treatment for severe asthma patients. Currently, based on the clinical manifestations and characteristics of pathophysiology and imaging studies, the clinical phenotypes of severe asthma are proposed as follows (Table 2).

\section{Early-onset allergic asthma}

The age-of-onset is a useful determinant for adult asthma phenotypes (81). Although a definite age cut-off remains lacking for early-onset allergic asthma, this phenotype usually includes most of adult asthma with childhood onset. In general, asthma patients with this phenotype generally have medical or family history of allergy (e.g., allergic rhinitis or allergic dermatitis) $(81,82)$, positive skin prick tests, and show good response to glucocorticoids $(83,84)$. The elevated levels of proinflammatory Th2 cytokines (IL-4, IL-5 and IL-13) and Th2-associated inflammatory biomarkers (induced sputum eosinophils, FeNO, total serum IgE and periostin) (85-87) suggest that asthma patients with this phenotype may benefit from inflammation-targeted therapy.

\section{Late-onset persistent eosinophilic asthma}

Persistent eosinophilic airway inflammation is commonly seen in the phenotype of late-onset persistent eosinophilic asthma $(82,88)$. Asthma in adults of this phenotype typically occurs later in life, and is more severe at onset, frequently accompanied with medical history of rhinosinusitis or nasal polyps (82). Even though a history of allergy is not present, the increased levels of Th2-associated inflammatory mediators (e.g., IL-5, IL-13 and FeNO) may be detected and often be linked to comorbidities such as nasal polyps (23). Patients of this phenotype often show "corticosteroid resistance" (89), but mostly would experience significant improvements in symptoms and lung function when given systemic corticosteroids. Still, these patients could benefit from the use of glucocorticoids (90-92).

\section{Frequent exacerbators}

Acute exacerbation is common in severe asthma, though the number of episodes varies across different phenotypes. Frequent asthma exacerbators are usually smokers, with worse control of asthma, lower quality of life, higher levels of $\mathrm{FeNO}$ and sputum eosinophils, faster decline in pulmonary function, and greater ICS use. Attention on these patients may be clinically relevant for monitoring of asthma, reducing future risk of acute exacerbations, and evaluating prognosis $(93,94)$. This phenotype, previously described as brittle asthma, falls into two types. Type I generally refers to the scenario where high variability peak expiratory flow ( $\mathrm{PEF}>40 \%$ ) persists despite use of high-dose ICS, commonly seen in female patients aged 15-55 years old and with history of allergy and positive skin prick test; Type II generally refers to the scenario where a sudden exacerbation occurs without any significant prodrome and notwithstanding that the asthma is well controlled, and rapidly progresses into a life-threatening condition. In-depth identification of these two types of asthma can be of great importance in effectively assessing the risk of exacerbations and educating the asthma patients on allergen avoidance and first-aid measures.

\section{Asthma with persistent airflow limitation}

Patients with this phenotype suffer more severe impairment of pulmonary function, and some may gradually develop "fixed" or "persistent" airflow limitation. The risk factors include adult onset, male gender (95), smoking (90), environmental exposures (e.g., occupational exposure) (96), inadequate ICS therapy during acute exacerbation of asthma (97), low $\mathrm{FEV}_{1}$ baseline (98), chronic mucus hypersecretion (98) and persistent eosinophilic inflammation in blood and sputum (98). In addition, this phenotype may be associated 
Table 2 Clinical features and therapeutic responsiveness in severe asthma phenotypes

\begin{tabular}{|c|c|c|}
\hline Phenotypes & Clinical features & Therapeutic responsiveness \\
\hline $\begin{array}{l}\text { Late-onset persistent } \\
\text { eosinophilic asthma }\end{array}$ & $\begin{array}{l}\text { - Adults with late onset } \\
\text { - Usually severe at onset } \\
\text { - History of rhinosinusitis and nasal polyps } \\
\text { - IL-5, IL-13 and FeNO levels may be elevated }\end{array}$ & Poor glucocorticoids sensitivity \\
\hline $\begin{array}{l}\text { Asthma with persistent airflow } \\
\text { limitation }\end{array}$ & $\begin{array}{l}\text { - Adult-onset, male } \\
\text { - Environmental exposures such as tobacco smoke and } \\
\text { occupational pollutants } \\
\text { - Low FEV } 1 \text { baseline level } \\
\text { - Chronic mucus hypersecretion } \\
\text { - Persistent eosinophilic inflammation in blood and sputum } \\
\text { - Frequent exacerbations and inadequate ICS treatment }\end{array}$ & $\begin{array}{l}\text { Need for more corticosteroids, including } \\
\text { oral preparations }\end{array}$ \\
\hline
\end{tabular}

Th, T helper cells; FeNO, fractional exhaled nitric oxide; IL, interleukin; IgE, immunoglobulin E; $F V_{1}$, forced expiratory volume in the first second; ICS, inhaled corticosteroids.

with high levels of proinflammatory biomarkers (e.g., sputum periostin) (99). Asthma patients with this phenotype usually report greater use of inhaled/oral corticosteroids.

\section{Obesity-related asthma}

Obesity, considered as a risk factor of asthma, may affect airway inflammation and asthma control. Compared with the normal-weighted, obese patients with severe asthma usually present with worse lung function (e.g., lower FVC), are more likely to have concomitant eczema or GERD but less likely report a history of nasal polyps. The total serum $\mathrm{IgE}$ in these patients decreases along with greater BMI. Meanwhile, obese asthmatics appear more dependent on systemic corticosteroids and daily use of as-needed shortacting beta-2 agonists (100). 


\section{Diagnosis and assessment of severe asthma}

Given great differences in asthma patient perception of symptoms, adherence to treatment, medication administration techniques, as well as numerous factors that affect asthma control, a diagnosis of severe asthma should be made only after regular treatment and follow-up by asthma specialists (101).

\section{Items for diagnosis and assessment}

Patients with severe asthma should undergo a careful and allrounded assessment, using major items as listed in Table 3.

\section{Steps for diagnosis and assessment}

The following four steps are recommended to diagnose and assess severe asthma $(102,103)$.

\section{Determining the diagnosis of asthma}

A typical medical history may prompt for the diagnosis of asthma in most patients. However, severe asthma may be more complicated in clinical manifestations, less characteristic of typical asthma, and therefore readily confused with other asthma-like diseases. While the diagnosis of severe asthma should be made in accordance with the criteria in GINA and Chinese guidelines for the diagnosis and treatment of asthma, special notes on two aspects are yet to emphasize: (I) all severe asthma patients need to undergo a complete pulmonary function test that includes bronchial provocation test and/or bronchodilation tests, diffusion capacity, as well as monitoring of peak flow rate. If necessary, the pulmonary function test needs reevaluation in these patients after a course of therapeutic trial; and (II) imaging studies of the chest, high-resolution computerized tomography (HRCT) in particular, are not routinely recommended as a diagnostic tool, regardless of their high value in differentiating asthma from other lung disorders. HRCT can be preserved for those with atypical symptoms, such as massive sputum, rapid decline in lung function, and reduced diffusion capacity.

Certain diseases with clinical manifestations that mimick asthma need careful study (Table 4).

\section{Identifying severe asthma}

Asthma control should be subject to comprehensive and all-rounded assessment according to GINA criteria. The common features of uncontrolled severe asthma are: (I) poor symptom control: ACQ score $>1.5$, ACT score $<20$,
Table 3 Major items for diagnosis and assessment of severe asthma

History of asthma

- Age of onset

- Family history of asthma

- Treatments given, and the treatment responses

- Frequency and severity of acute exacerbation, number of acute exacerbations requiring hospital stay and ICU admission

Environmental exposure

- Allergens, occupational factors, chemical irritants and air pollution

- History of smoking

Comorbidities and confounding factors

- Rhinosinusitis, with/without surgical history of nasal polyp resection

- Concomitant medications: Aspirin, NSAIDs, beta-receptor antagonist, $\mathrm{AECl}$ and estrogen

- Gastroesophageal reflux disease

- Obstructive sleep apnea-hypopnea syndrome

- Menstruation and asthma

Patient adherence

History of psychosomatic disorders

- Psycho-social environment

Keynotes for physical examination

- Body mass index

- With/without comorbidities, such as nasal polyps

- With/without other possible diagnosis, such as heart failure

Presence of drug-related adverse effects

Asthma assessment

- Pulmonary function: bronchodilation test or challenge test, lung volume and diffusion capacity test

- Baseline assessment

- General health and asthma control questionnaires

- Serum total IgE and peripheral blood eosinophil count

- Allergen-specific skin prick test

- Airway inflammation: induced sputum eosinophil count and FeNO level

Investigations for comorbidities: e.g., 24-hour pH monitoring of esophagus and HRCT

NSAIDs, non-steroidal anti-inflammatory drugs; ACEI, angiotensin converting enzyme inhibitor; IgE, immunoglobulin $\mathrm{E}$. 
or in consistency with a GINA-defined uncontrolled asthma; (II) frequent exacerbations: the need for 2 or more burst of systemic corticosteroids in the previous year ( $>3$ days each); (III) serious exacerbations: at least one hospitalization or ICU stay or the need for mechanical ventilation related to asthma in the previous year; (IV) persistent airflow limitation withholding $\mathrm{FEV}_{1}<80 \%$ predicted and $\mathrm{FEV}_{1} / \mathrm{FVC}$ below lower limit of normal despite adequate bronchodilator use $(104,105)$; and (V) asthma is maintained under control with high-dose ICS or systemic corticosteroids (or biologic pharmaceutical agents) but worsens with lower dosage.

\section{Identifying the presence of comorbidities and risk factors}

Comorbidities and risk factors that affect asthma control may be present in patients with severe asthma. Before assessing these aspects, patient adherence and inhalation techniques should be evaluated in the first place. The adherence to oral medications can be assessed by measuring the serum levels of cortisol or theophylline, and that with inhaled medications, by using an inhaler mounted with electronic monitor or connected to a smartphone application via Bluetooth. For non-compliant patients, further patient-physician communications are needed, such that individualized management strategies could be developed (106).

In addition to treatment adherence, comorbidities associated with severe asthma include atopy and allergies (including sensitization to fungi), rhinosinusitis, nasal polyps, obesity, and neuropsychiatric factors (esp. anxiety and depression). Active or passive smoking and air pollution are also significant causes of poor asthma control (107).

\section{Distinguishing among asthma phenotypes}

The phenotypes of asthma result from the interaction between genetic and environmental factors. Although a widely accepted definition of specific asthma phenotypes remains so far unavailable, identifying certain features of an asthma phenotype will favor predicting the natural course of asthma in different patients, and may ultimately lead to decision on targeted therapy of other effective treatments. Since response to treatments varies greatly among asthma phenotypes, properly distinguishing among these phenotypes may contribute to more specific treatment for asthma patients (10).

Figure 4 shows the flowchart for diagnosis and assessment of severe asthma.
Table 4 Diseases likely misdiagnosed as severe asthma

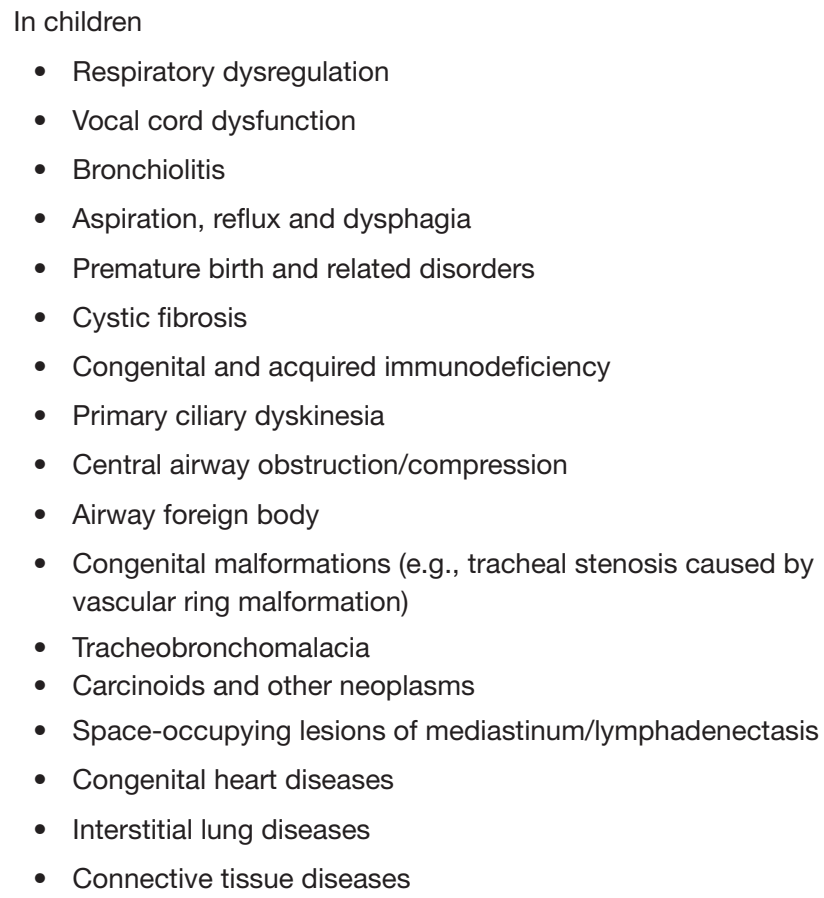

- Congenital malformations (e.g., tracheal stenosis caused by vascular ring malformation)

- Tracheobronchomalacia

- Carcinoids and other neoplasms

- Space-occupying lesions of mediastinum/lymphadenectasis

- Congenital heart diseases

- Interstitial lung diseases

- Connective tissue diseases

In adults

- Respiratory dysregulation

- Vocal cord dysfunction

- Chronic obstructive pulmonary disease, chronic bronchitis and emphysema

- Hyperventilation syndrome with panic attacks

- Upper airway obstruction

- Chronic congestive heart failure

- Drug-related adverse effects [as with angiotensin converting enzyme inhibitor (ACEI)]

- Bronchiectasis

- Cystic fibrosis

- alpha-1 antitrypsin deficiency

- Allergic pneumonitis

- Eosinophilic lung infiltration

- Pulmonary embolism

- Viral bronchitis

- Post-influenzal cough

- Postnasal drip syndrome

- Bronchial injury/lesions (e.g., amyloidosis, carcinoid and tracheal stenosis)

- Allergic bronchopulmonary aspergillosis (ABPA)

- Secondary tracheobronchomalacia

- Carcinoid syndrome

- Churg-Strauss syndrome

- Hyperthyroidism 


\section{Treatment strategies}

\section{Education and management}

Asthma education aims to improve patient adherence to treatment, mastery of inhalation techniques, and to promote their self-management capacity.

\section{Improving patient adherence to treatment}

This is a major concern in clinical practice as how to do. The solution starts by evaluating the patient adherence and sorting out what preludes the poor adherence, until a adherence-improving strategy could be tailored according to specific problems with the patient (1). Furthermore, developing inhaler devices with a reminder for missed doses, and promoting the use of interactive voice response (IVR) system and mobile-internet healthcare platform may also add to improving patient adherence.

\section{Mastering inhalation techniques}

A variety of inhalers are commercially available. Improper use of inhalation devices may result in poor asthma control, increased risks for acute asthma exacerbations and drugrelated adverse effects, or even patient refusal to receiving inhaled medications. Thus, it is important to master the proper usage of inhalation devices (108). International studies have found that $70-80 \%$ of the patients were unable to use their inhalers correctly; not only so, a number of physicians failed to instruct their patients on how to use the inhalers properly (109), pinpointing the great necessity for patient training on the inhaler use. To this end, the 2014 GINA recommended (1) that the choice of inhalation device should be based on drug availability, patient conditions and costs, ideally with patient preference, and that using pressurized metered dose inhaler (pMDI) connected to a spacer may improve drug delivery and reduce drug-related adverse effects.

\section{Promoting self-management capacity}

Asthma self-management under effective guidance from a health education team (including physicians, pharmacists, and nurses) may dramatically lower debilitation from asthma, and reduce one to two thirds of asthma-related hospitalizations, emergency and unscheduled office visits, missed work/school days, and nocturnal wakening (1). An asthma action plan developed with assistance of physicians will help meet these goals. A good action plan should include self-monitoring, periodic evaluation of treatment regimens and asthma control, strategies on how to promptly adjust the treatment regimen to maintain asthma control when symptoms and/or PEF indicate a change in asthma control level and how to get timely treatment. The most commonly used tools for assessment and monitoring of asthma include asthma control test (ACT), portable PEF meter and asthma diary. Proper use of PEF meter and an accurately written asthma diary are both effective in preventing and reducing asthma attacks. Information available in asthma diary helps physician and patient properly assess the asthma severity, control level and treatment response (110), sort out how the asthma attacks relates to treatment, and thereby facilitates the selection and adjustment of medications.

\section{Environment control}

\section{Effective allergen reduction or avoidance}

(I) House dust mites: hot wash your bedsheets and blankets weekly and dry them in a dryer or direct sunlight. Encase all pillow and mattress with protector covers. Choose floorboards rather than carpets, especially for the bedrooms (if possible, use a vacuum cleaner with filter, eliminate the mites with acaricides or tannic acids, but make sure that the asthma patient is out of the house when doing these). (II) Furry animals: use an air filter. Do not allow them in the house, or at the least, not in the bedrooms. Give them a shower on a regular basis. (III) Cockroach: sweep the house thoroughly at times. Pesticide sprays should be used when the asthma patient is out of the house. (IV) Outdoor pollens and molds: close doors and windows, and stay indoors when outdoor pollens and molds levels are high. Wear a mask while going outdoors. If possible, consider a change in the residential environment. (V) Indoor molds: lower indoor humidity. Clean up any damp areas frequently. (VI) Occupational allergens: avoid exposure timely when any occupational allergen is identified to prevent worsening of the health problem.

\section{Reduction or avoidance of harmful irritants in the air} Reduction or avoidance of harmful irritants in the air, such as nitrogen oxides, ozone, sulfur dioxide, acidic aerosols, formaldehyde and biological pollutants (e.g., endotoxins).

\section{Smoking cessation}

Smoking can mechanistically alter the airway inflammation and render it less responsive to glucocorticoids $(111,112)$. Exposure to tobacco smoke is associated with poor asthma outcomes (113). Therefore, each intended cigarette 


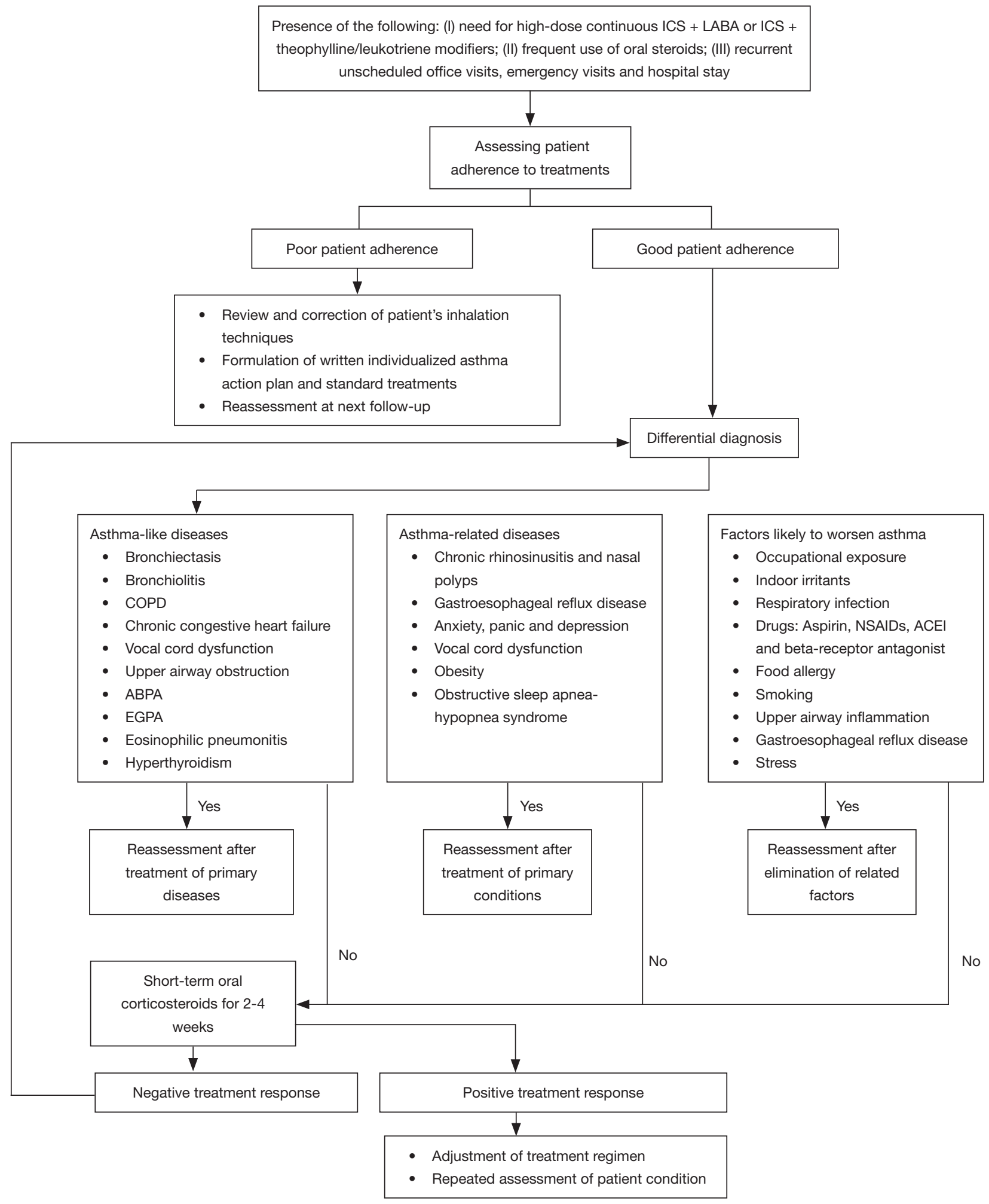

Figure 4 Flowchart of diagnosis and assessment of severe/refractory asthma. ICS, inhaled corticosteroids; LABA, long-acting beta2 receptor agonist; COPD, chronic obstructive pulmonary disease; ABPA, allergic bronchopulmonary aspergillosis; EGPA, eosinophilic granulomatosis with polyangiitis; NSAIDs, non-steroidal anti-inflammatory drugs; ACEI, angiotensin converting enzyme inhibitor. 
quitter should be encouraged to receive consultation, and medications as needed.

\section{Psychotherapy}

\section{Supportive psychotherapy}

(I) Cognitive reconstruction: as human emotions are mediated by cognitive process, maladaptive emotions are therefore associated with maladaptive cognition. Correction of patients' understanding about their disease, family, life events and the society, would help ameliorate or eliminate their mental problems; (II) psychological counseling: this involves assessing the patients' mental state, helping them clearly understand the etiologies, current treatments and the prognosis of asthma, building up their confidence to overcome asthma by comforting and reassuring them; (III) family therapy: family members of the asthma patients, esp. parents of the asthmatic child or spouse of the asthmatic adult, should avert developing dislike of or discrimination against the patient; however, parents should not overly coddle their children, either, in case that the latter develop psychological dependence.

\section{Pharmaco-psychotherapy}

For patients with mental disorders that failed supportive psychotherapies, anxiolytics or antidepressants may be considered to relieve their negative emotions, so as to help asthma control.

\section{Medications for asthma}

\section{Corticosteroids}

Combined use of high-dose ICS and oral corticosteroids is often indicated in severe asthma.

\section{ICS}

In general, a higher dose of ICS offers more potent antiinflammatory action. Definitions for high daily doses of ICS, as defined by the 2015 GINA, are shown in Table 5 (1).

Individual difference exists in the dose-response relationship of ICS. Continued increase in ICS dose $(>2,000 \mu \mathrm{g} / \mathrm{d}$ beclomethasone equivalent $)$ and administration of ultra-fine ICS formulations might be more effective for severe asthma, and meanwhile associated with less use of systemic corticosteroids, but so far these have been bolstered only by weak evidences $(2,114)$. For patients with corticosteroid-dependent asthma, highdose ICS therapy may lead to lower maintenance doses of oral corticosteroids and hence less steroid-related adverse effects. Ciclesonide, used as a drug precursor, is converted to a pharmacologically active metabolite (des-ciclesonide) by esterases in lung tissues after inhalation, with 100-fold activity compared with its parent compound. Ciclesonide spray could be administered once daily, owing to the finesize drug particles that enables far-reaching access to distal bronchioles and alveoli, with a $>50 \%$ deposition rate in both lungs. Ciclesonide quickly gets metabolized in the lungs but rarely becomes activated in the oropharynx, and thus shows little systemic and topical side effects (115). Satisfactory therapeutic efficacy and safety profiles of ciclesonide in severe asthma have been demonstrated by clinical trials $(115,116)$. However, it is noteworthy that extremely large dose of ICS may increase the risk for adverse effects, including adrenal suppression, and growth retardation in children.

\section{Oral corticosteroids}

For severe asthma patients whose symptoms remain uncontrolled on ICS with high maintenance dose, addition of oral corticosteroids for maintenance therapy is usually indicated. In corticosteroid-dependent asthma, determining a minimal maintenance dose of oral corticosteroids for long-term use should be indispensable. A daily use of $\leq 7.5 \mathrm{mg}$ prednisone or equivalent has been reported to be effective for severe asthma in adults. While biomarkerbased guidance of corticosteroid use in clinical settings has been proposed, the value of sputum eosinophil counts and/ or FeNO level in management of severe asthma remains controversial. Systemic corticosteroids use is associated with higher risks for bone fractures and cataract. The increase in body weight following use of systemic corticosteroids also compromises asthma control. Therefore, patients on longterm systemic corticosteroids or high-dose ICS should be monitored for body weight, blood pressure, blood glucose, eye conditions, bone density, and growth status (in children) (2).

\section{Long-acting intramuscular corticosteroids}

Intramuscular administration of triamcinolone $(3 \mathrm{~mL})$, a long-acting corticosteroid, has been reported to be useful in corticosteroid-insensitivity severe asthma in literature $(2,90)$. Unfortunately, the drug-related adrenocortical suppression and dependence liability alert for avoidance of triamcinolone misuse.

\section{Beta-2 receptor-agonists}

Chronic airflow obstruction may persist in many severe asthma patients treated on ICS plus short-acting beta-2 agonists (SABAs) and/or long acting beta- 2 agonists (LABAs). Using LABA in combination with stepwise 
Table 5 Age group-specific definition for high daily doses of ICS

\begin{tabular}{lcc}
\hline \multirow{2}{*}{ ICS } & \multicolumn{2}{c}{ Threshold of high daily-dose $(\mu \mathrm{g})$} \\
\hline Beclomethasone dipropionate (CFC) & $6-12$ years old & $>12$ years old \\
\cline { 2 - 3 } Beclomethasone dipropionate (HFA) & $>400$ & $>1,000$ \\
Budesonide (DPI) & $>200$ & $>400$ \\
Budesonide (aerosol) & $>400$ & $>800$ \\
Ciclesonide (HFA) & $>1,000$ & $>320$ \\
Fluticasone propionate (DPI) & $>160$ & $>500$ \\
Fluticasone propionate (HFA) & $>400$ & - \\
Mometasone furoate (HFA) & $>500$ & $>440$ \\
Triamcinolone acetonide & $>440$ & $>2,000$ \\
\hline
\end{tabular}

ICS, inhaled corticosteroids; CFC, chlorofluorocarbon propellant; HFA, hydrofluoroalkane propellant; DPI, dry-powder inhaler.

increasing dose of ICS may further improve asthma control. When not combined with ICS, overdose of beta-2 agonists alone (SABA and/or LABA) may cause worsening of asthma. Importantly, monotherapy with beta-2 agonist exceeding the recommended dose would increase asthma-related mortality (2). Subcutaneous injection of terbutaline may help control attacks of severe asthma and reduce hospital admissions (117). In certain cases, subcutaneous self-administration of adrenaline with preloaded syringes can be a treatment for type II brittle asthma (118).

For management of severe asthma, ICS in combination with LABA (salmeterol or formoterol) provides significantly greater efficacy compared with either alone. Currently in clinical settings, the widely used LABA/ICS combination products include budesonide/formoterol $(320 / 9 \mu \mathrm{g})$, fluticasone/salmeterol $(500 / 50 \mu \mathrm{g})$ and beclomethasone propionate/formoterol $(100 / 6 \mu \mathrm{g})$. Formulations combining ICS and certain once-daily LABAs (including indacaterol, carmoterol, olodaterol, and vilanterol), are evaluated in ongoing clinical trials. Combination inhalers of fluticasone furoate/ vilanterol and mometasone /indacaterol are now commercially available (115). Studies have demonstrated the therapeutic efficacy of fluticasone propionate/formoterol and fluticasone furoate/vilanterol in patients with severe asthma (119-121).

\section{Anticholinergics}

Ipratropium spray, a short-acting anticholinergic, may relieve wheezing and reduce adverse effects related to overdose beta-2 agonists (e.g., tremors and palpitations) in severe asthma patients (2). In severe asthma patients treated on moderate-to-high dose ICS with/without LABA, addition of tiotropium, a long-acting muscarinic antagonist (LAMA), may reduce air trapping and acute exacerbations (122), and also improve the lung function $(123,124)$. Clinical trials with the once-daily glycopyrrolate and umeclidinium, and the twice-daily aclidinium bromide, are ongoing. Triple therapy with budesonide, formoterol, tiotropium (LABA/LAMA/ICS) has been approved for asthma in several countries. Other triple combinations, such as "budesonide, formoterol and glycopyrrolate bromide", "mometasone, indacaterol and glycopyrrolate bromide" and "fluticasone furoate, vilanterol and umeclidinium bromide" formulations, are now in clinical trials (122).

\section{Theophyllines}

For patients with severe asthma, a combination of theophylline with ICS can facilitate asthma control. Addition of theophylline to low-dose ICS may dramatically improve PEF rate and asthma control in smokers with corticosteroidinsensitivity asthma. However, the role of theophyllines in severe asthma has not yet been delineated (2).

\section{Leukotriene receptor antagonists (LTRAs)}

A few studies on LABA-naive patients with moderate-tosevere asthma have shown certain improvement in lung function following combination use of ICS and LTRAs. However, data remain inconclusive regarding whether aspirin-allergic patients show better response to LTRAs compared with non-aspirin-allergic subjects (2). 
Immunosuppressants and antimetabolites

Clinical studies have indicated that, methotrexate may remarkably reduce the dosage of oral corticosteroids in asthma patients who has developed dependence to the latter, usually by a mean of $50 \%$, after 4 to 5 months of continuous treatment. Given their adverse effects, the use of these medicines should be reviewed and guided by specialists. Other drugs in this category include intravenous immunoglobulin, depsone, colchicines, hydroxychloroquine and cyclosporine-A. A lack in high-level evidences for the therapeutic efficacy and safety precludes the routine use of these agents.

\section{Other medications}

\section{Macrolides}

Low-dose oral macrolides (e.g., clarithromycin, azithromycin) have been reported to be beneficial in treatment of severe asthma by attenuating neutrophildominated airway inflammation and hyperresponsiveness; in light of potential drug-resistance, drug-related adverse effects (ototoxicity, QT interval prolongation) and uncertainty in therapeutic gains, though, macrolides are not recommended for patients with severe asthma (2).

\section{Antifungals}

Antifungal therapy in severe asthma complicated with recurrent allergic bronchopulmonary aspergillosis (ABPA) may reduce the risk of acute asthma exacerbation and improve symptoms. In contrast, antifungals are not recommended for as a treatment in non-ABPA-complicated severe asthma, for concerns over the interactions between antifungals and other medications, drug related adverse effects, increased medical costs, as well as uncertainty in clinical benefits.

\section{Overview of novel therapeutic agent and approach}

\section{Biological agents}

The chronic airway inflammation in asthma is driven mainly by an excessive Th2 response involving higher levels of IL-4, IL-5, IL-13 and IgE in the circulation, and elevated counts of eosinophils in the airway. However, normal levels of circulatory Th2 cytokines have been reported in part of asthma patients. Therefore, asthma can be classified into two phenotypes based on Th2 cytokine levels: Th2-high and Th2-low. Until recently, biological agents used in targeted therapy for the Th2-high phenotype has been one of the hot topics in research and development of novel anti-asthmatic medications. Biological therapy brings new hope to patients with severe Th2-driven asthma.

\section{Anti-IgE monoclonal antibody (mAb)}

Anti-IgE mAb specifically binds to the FceRI sites of $\operatorname{IgE}$ and thereby interferes with $\operatorname{IgE}$ binding to a number of target cells such as mast cells, basophils, and thus inhibits IgE-mediated activation and degranulation of mast cells and basophils. Omalizumab is the first approved anti-IgE $\mathrm{mAb}$ for treatment of asthma. In majority of clinical studies, Omalizumab has been confirmed to lower the frequency of exacerbation of severe asthma, and to a certain extent, improve life quality, asthma symptoms and the pulmonary function $(125,126)$. As early as in the 2006 updates on GINA, Omalizumab has been recommended as the treatment step 5 for asthma, i.e., for allergic severe asthma which remains symptomatically uncontrolled on high-dose ICS plus LABA and other controller therapy. Currently, the latest GINA update has re-defined this treatment step 5 to an "add-on" therapy for asthma, meaning that it is used as an optional therapy added on conventional medicines (such as ICS/LABA) and no longer used separately.

The optimal dosage and frequency for Omalizumab therapy depend on serum $\operatorname{IgE}$ level and body weight of the subject, usually ranging from 70 to $600 \mathrm{mg}$ per dose for each subcutaneous injection in every 2 to 4 weeks apart. Long-term Omalizumab is with good safety profiles and does not increase the risk of malignancies. The adverse effect is chiefly the topical reaction at the injection site. Alerts should be prompted for the hypersensitivity reaction after injection, as life-threatening allergy was reported in sporadic cases. A close observation of the patient is therefore mandatory after injection.

\section{Anti-IL-5 mAb}

IL-5 is the most important cytokine which mediates eosinophil production from differentiated stem cells in bone marrow and eosinophil proliferation in the human body. Anti-Il-5 mAb works by inhibiting the proliferation of eosinophils through IL-5 blockage. Early trials with anti-IL-5 mAb failed to meet primary clinical endpoints. Later trials with new study design to include severe hyper-eosinophilic asthma patients show that antiIL-5 mAb therapy results in nearly $50 \%$ reduction in 
acute exacerbations, one-third less emergency visits or hospitalization, lower dosage of oral corticosteroids, as well as improvements in asthma control and lung function $(127,128)$. Towards the end of 2015 , anti-IL-5 mAb (Mepolizumab) has been approved for use in the US and EU. Other related mAbs are now in development, such as Reslizumab (anti-IL-5 mAb) and Benralizumab (anti-IL-5 receptor $\mathrm{mAb})$.

\section{Anti-IL-4 and anti-IL-13 mAbs}

IL-4 and IL-13 are important Th2 cytokines with key roles in the development and progression of inflammation in asthma. Research findings with anti-IL-13 $\mathrm{mAb}$ (Lebrikizumab) for treatment of severe asthma showed that Lebrikizumab reduces over $50 \%$ of acute exacerbations in severe asthma patients with high serum periostin (a marker of Th2-dependent inflammation) levels, but appears ineffective in those with low serum periostin levels (129), suggesting that anti-IL-13 mAb can be clinically effective only when used in those with Th2-high phenotype of asthma.

Anti-IL-4 receptor mAb (Dupilumab) may specifically bind to the IL-4 receptor alpha subunit and thereby block the biological actions of IL-4. In a clinical study on moderate-to-severe hypereosinophilic asthma (130), Dupilumab was shown to offer dramatic treatment outcomes by reducing nearly $90 \%$ of acute exacerbation. However, as that study was limited by sample size, the efficacy of Dupilumab needs further validation with more patients included in the future.

In addition to these, many other biological agents targeting various checkpoints in asthma inflammation are now in clinical trials with efficacy pending verification. Overall, the above mentioned Th2 response-targeted agents may reduce acute exacerbation of severe asthma by more than $50 \%$, and to a certain extent, improve life quality, lung function and asthma symptom scores. The launch of these novel biological agents will bring new hope to patients with Th2-high phenotype of severe asthma, and will also herald a new era of individualized asthma treatment. However, asthma is a highly heterogeneous entity with complicated inflammation involved within. A single anti-inflammation approach would be difficult to account for complete control of the development and progression of inflammation in asthma. Therefore, currently available biological agents are used merely as a supplementary to severe asthma treatments, and yet should not substitute for conventional medications.

\section{Bronchial thermoplasty (BT)}

BT is a novel non-pharmacological, bronchoscopic intervention for asthma, designed to reduce the mass of ASM, attenuate bronchoconstriction (131-135), enhance asthma control, improve life quality, and cut down the doses of pharmacotherapy (136-139). In light of its increasingly confirmed therapeutic efficacy and safety profiles by studies (140-143), BT was officially approved for treatment of severe asthma in China in March 2014. Mechanistic study (144) also shows that BT reduction of the ASM mass may lead to less production of angiogenic factors, thereby delaying the progression of airway remodeling.

As well-demonstrated by international studies, despite the post-thermoplastic increases in short-term risk for worsening of asthma, in adverse respiratory events (e.g., post-procedural dyspnea, cough, wheezing, sputum, night awakening, hemoptysis, upper airway infection, atelectasis, lung abscess and other procedure-related events), and development of non-specific symptoms such as fever, headache and vocal hoarseness $(136-139,145,146)$, these usually resolve within 7 days of the procedure (147). Over 5 -year follow-up observations, BT was not found to be associated with any long-term complications $(148,149)$. Meanwhile, asthma patients who underwent BT had significantly less asthma-related emergency visits and hospitalization, and none of them had post-thermoplastic airway architectural changes (e.g., bronchiectasis or airway constriction) under HRCT and bronchoscopy (136-139,145,150).

In April 2010, the US Food and Drug Administration (FDA) approved BT for the treatment of severe persistent asthma in patients 18 years and older whose asthma is not well controlled with adequate ICS and LABA therapy. In 2014 and 2015 updates of GINA, recommendation about BT were upgraded to level B evidence, such that BT has been listed as a conventional option in the treatment Step 5 , in parallel with anti-IgE therapy and oral glucocorticoids, for proposed use in certain adults with severe asthma.

Patient selection is the key to successful BT, and also affects the short-term safety and long-term outcomes of the treatment. Currently, Chinese experience with BT in clinical settings shows that, BT can be considered for poorly-controlled asthma patients who have been regularly on GINA Step 4 or 5 treatments for at least half a year, or those whose asthma control remains well on regular GINA Step 4 or 5 treatments but is repeatedly lost when de-escalating the treatment (esp. When tailing-off oral 
corticosteroids). The feasibility of BT could also be investigated in extreme cases of asthma where a range of risk factors for recurrent exacerbation and fluctuation in patient condition are present, avoidance from environmental irritation is not possible, or patient adherence seems uncorrectably poor (151).

Perioperative management is another important aspect to guarantee BT safety. Perioperative management is also an important aspect to ensure the patient safety in BT. Prior to the procedure, the patient should undergo a pulmonary function test for assessing the severity of asthma, as well as the risk and safety of $\mathrm{BT}$. A lower $\mathrm{FEV}_{1}$ value may mean a greater procedural risk. In general, the BT safety would be high in patients on regular asthma medication plus $\mathrm{FEV}_{1}>50 \%$ predicted or $\mathrm{FEV}_{1}>1 \mathrm{~L}$ by baseline pulmonary function test, but could be challenging in those whose $\mathrm{FEV}_{1}$ lingers at or below $40 \%$ predicted after systemic glucocorticoids or bronchodilators. Moreover, the perioperative management becomes more demanding in patients with more comorbidities. Therefore, for instance, the blood pressure and blood glucose need to be under well control before BT; severe asthma comorbid with OSAHS needs more alerts against the greater anesthesia risk. Comorbidities in severe asthma also impose a major risk for fluctuations in patient condition, and thus, each patient with severe asthma should be evaluated for hypertension, diabetes, obesity, OSAHS, rhinosinusitis, and GERD, prior to the procedure. To ensure the BT safety and efficacy, efforts should be exerted to a number of important issues, i.e. prudent identification of surgical indications, proper selection of candidates, pre-operative assessment of pulmonary lung functions and comorbidities, rigorous adherence to procedure protocols, use of suitable anesthesia, and post-thermoplastic follow-up (152).

Ever since the approval of BT for clinical use by China in 2014, this technique has been increasingly introduced in Chinese hospitals. A Chinese registry study for BT is now ongoing. However, the number of case reports with BT in this country remains limited. Clinical data published in $2016(153,154)$, which included thus far the largest case series and longest follow-up in China, indicated significant reductions in one-year exacerbation rate (by $79.4 \%$ ), hospital admission due to exacerbation (by $89.4 \%$ ) and oral use of corticosteroids, compared with the previous year.

However, the long-term efficacy and safety of BT requires validation in longer time of follow-up observation, in well-designed randomized double-blind controlled trials with large sample size, and in clinical registry studies involving participation of asthma patients (155).

Regardless of current advances, our understandings about the development, progression and prognosis of severe asthma remain inadequate. Research on the prevention and management of severe asthma continues to be important for Chinese pulmonologists. Collaborative research projects are expected to obtain the baseline data about clinical manifestations, control, and disease burden of severe asthma in China, explore the risk factors and clinical phenotypes of severe asthma specific to Chinese population, propose novel biomarkers for asthma diagnosis and phenotyping, set up a diagnostic and evaluation algorithm, and develop phenotype-based individualized treatment strategies (bolstered by comprehensive treatments) that includes targeted therapy and BT. All these should help to improve control asthma, patients' quality of life, and burden of disease, and ultimately, provide evidences for precision treatment of severe asthma in this country (10).

\section{Acknowledgements}

This consensus document was translated from a Chinese version by Dr. Prof. Guangqiao Zeng and his colleagues (Chu Pei, Rui Wang and Kangni Chen), with permission and authorization from Prof Jiang-Tao Lin on behalf of China Asthma Alliance. The translators aim to promote and distribute this consensus to a wider international scientific audience.

Experts participating in panel discussion of this consensus document are (sorted by surnames alphabetically): Meiling Jin (Department of Respiratory Medicine, Zhongshan Hospital, Fudan University, Shanghai, China), Lingfei Kong (Department of Respiratory Medicine, First Affiliated Hospital of China Medical University, Shenyang, China), Chen Qiu (Department of Respiratory Medicine, Shenzhen People's Hospital, Shenzhen, China), Huaping Tang (Department of Respiratory Medicine, Qingdao Municipal Hospital, Qingdao, China), Hua Xie (Department of Respiratory Medicine, General Hospital of Shenyang Military Region, Shenyang, China), Yadong Yuan (Department of Respiratory Medicine, Second Affiliated Hospital of Hebei Medical University, Shijiazhuang, China), Qinglin Zhang (First Affiliated Hospital of Guangzhou Medical University, Guangzhou, China), and Nanshan Zhong (Department of Respiratory Medicine, First Affiliated Hospital of Guangzhou Medical University, Guangzhou, China). 
Funding: This work was supported by the Capital Key Science Program for Health Development (2016-1-4061); Beijing Science and Technology Commission Capital Key Program for Clinical Application Research (2015-BKJ-001).

\section{Footnote}

Conflicts of Interest: The authors have no conflicts of interest to declare.

\section{References}

1. Global Initiative for Asthma (GINA). Global strategy for asthma management and prevention (updated 2015). Available online: http://www.ginasthma.org, accessed November 202018.

2. Chung KF, Wenzel SE, Brozek JL, et al. International ERS/ATS guidelines on definition, evaluation and treatment of severe asthma. Eur Respir J 2014;43:343-73.

3. Hoskins G, McCowan C, Neville RG, et al. Risk factors and costs associated with an asthma attack. Thorax 2000;55:19-24.

4. Lin J, Feng X. Paying greater attention to the studies of disease burden of bronchial asthma. Zhonghua Yi Xue Za Zhi 2014;94:1201-3.

5. Lin JT. Moving forward to improve the diagnosis and treatment of refractory asthma.Zhonghua Jie $\mathrm{He} \mathrm{He} \mathrm{Hu}$ Xi Za Zhi 2010;33:561-2.

6. Asthma Workgroup, Chinese Thoracic Society. Expert consensus on diagnosis and management of refractory asthma. Zhonghua Jie He He Hu Xi Za Zhi 2010;33:572-7.

7. Proceedings of the ATS workshop on refractory asthma: current understanding, recommendations, and unanswered questions. American Thoracic Society. Am J Respir Crit Care Med 2000;162:2341-51.

8. Chung KF, Godard P, Adelroth E, et al. Difficult/therapyresistant asthma: the need for an integrated approach to define clinical phenotypes, evaluate risk factors, understand pathophysiology and find novel therapies. ERS Task Force on Difficult/Therapy-Resistant Asthma. European Respiratory Society. Eur Respir J 1999;13:1198-208.

9. Chung KF. New treatments for severe treatment-resistant asthma: targeting the right patient. Lancet Respir Med 2013;1:639-52.

10. Lin J, Zhao Q. Diagnosis, evaluation and individualized treatment of severe asthma. Zhonghua Yi Xue Za Zhi 2015;95:3088-90.
11. Su N, Lin JT, Wang WY, et al. A cross-section study of severe asthma in eight provinces of China. Zhonghua Nei Ke Za Zhi 2016;55:917-21.

12. Feng $X$, Lin J, Su N, et al. Risk factors of bronchial asthma among people aged over 14 years in China. Zhonghua Yi Xue Za Zhi 2014;94:1209-14.

13. Sullivan SD, Rasouliyan L, Russo PA, et al. Extent, patterns, and burden of uncontrolled disease in severe or difficult-to-treat asthma. Allergy 2007;62:126-33.

14. Martínez-Moragón E, Serra-Batllés J, De Diego A, et al. Economic cost of treating the patient with asthma in Spain: the AsmaCost study. Arch Bronconeumol 2009;45:481-6.

15. O'Neill S, Sweeney J, Patterson CC, et al. The cost of treating severe refractory asthma in the UK: an economic analysis from the British Thoracic Society Difficult Asthma Registry. Thorax 2015;70:376-8.

16. Kim SH, Kim TW, Kwon JW, et al. Economic costs for adult asthmatics according to severity and control status in Korean tertiary hospitals. J Asthma 2012;49:303-9.

17. Lin JT, Xing B, Tang HP, et al. A multi-center retrospective study of clinical characteristics and hospitalization costs of patients hospitalized for asthma exacerbation in China during 2013-2014. Zhonghua Jie He He Hu Xi Za Zhi 2017;40:830-4.

18. Wenzel SE, Schwartz LB, Langmack EL, et al. Evidence that severe asthma can be divided pathologically into two inflammatory subtypes with distinct physiologic and clinical characteristics. Am J Respir Crit Care Med 1999;160:1001-8.

19. Porsbjerg C, Lund TK, Pedersen L, et al. Inflammatory subtypes in asthma are related to airway hyperresponsiveness to mannitol and exhaled NO. J Asthma 2009;46:606-12.

20. Simpson JL, Scott R, Boyle MJ, et al. Inflammatory subtypes in asthma: assessment and identification using induced sputum. Respirology 2006;11:54-61.

21. Hastie AT, Moore WC, Meyers DA, et al. Analyses of asthma severity phenotypes and inflammatory proteins in subjects stratified by sputum granulocytes. J Allergy Clin Immunol 2010;125:1028-1036.e13.

22. Rogala B, Bozek A, Gluck J, et al. Prevalence of IgEmediated allergy and evaluation of Th1/Th2 cytokine profiles in patients with severe bronchial asthma. Postepy Dermatol Alergol 2015;32:274-80.

23. Saha SK, Berry MA, Parker D, et al. Increased sputum and bronchial biopsy IL-13 expression in severe asthma. J Allergy Clin Immunol 2008;121:685-91.

24. Sazonov AE, Petrovskii FI, Ivanchuk II, et al. IL-5 
expression in the sputum of patients with bronchial asthma. Bull Exp Biol Med 2003;135:374-6.

25. Brightling CE, Bradding P, Symon FA, et al. Mast-cell infiltration of airway smooth muscle in asthma. $\mathrm{N}$ Engl J Med 2002;346:1699-1705.

26. Balzar S, Fajt ML, Comhair SA, et al. Mast cell phenotype, location, and activation in severe asthma. Data from the Severe Asthma Research Program. Am J Respir Crit Care Med 2011;183:299-309.

27. Moore WC, Hastie AT, Li X, et al. Sputum neutrophil counts are associated with more severe asthma phenotypes using cluster analysis. J Allergy Clin Immunol 2014;133:1557-1563.e5.

28. McKinley L, Alcorn JF, Peterson A, et al. TH17 cells mediate steroid-resistant airway inflammation and airway hyperresponsiveness in mice. J Immunol 2008;181:4089-97.

29. Halwani R, Sultana A, Al-Kufaidy R, et al. Th-17 regulatory cytokines inhibit corticosteroid induced airway structural cells apoptosis. Respir Res 2016;17:6.

30. Cohen L, E X, Tarsi J, et al. Epithelial cell proliferation contributes to airway remodeling in severe asthma. Am J Respir Crit Care Med 2007;176:138-45.

31. James AL, Bai TR, Mauad T, et al. Airway smooth muscle thickness in asthma is related to severity but not duration of asthma. Eur Respir J 2009;34:1040-5.

32. Lo CY, Michaeloudes C, Bhavsar PK, et al. Increased phenotypic differentiation and reduced corticosteroid sensitivity of fibrocytes in severe asthma. J Allergy Clin Immunol 2015;135:1186-95.e1-6.

33. Wang CH, Huang CD, Lin HC, et al. Increased circulating fibrocytes in asthma with chronic airflow obstruction. Am J Respir Crit Care Med 2008;178:583-91.

34. Wan YI, Shrine NR, Soler AM, et al. Genome-wide association study to identify genetic determinants of severe asthma. Thorax 2012;67:762-8.

35. Gomez JL, Crisafi GM, Holm CT, et al. Genetic variation in chitinase 3-like 1 (CHI3L1) contributes to asthma severity and airway expression of YKL-40. J Allergy Clin Immunol 2015;136:51-58.e10.

36. Wenzel SE, Balzar S, Ampleford E, et al. IL4R alpha mutations are associated with asthma exacerbations and mast cell/IgE expression. Am J Respir Crit Care Med 2007;175:570-6.

37. Hawkins GA, Robinson MB, Hastie AT, et al. The IL6R variation Asp(358)Ala is a potential modifier of lung function in subjects with asthma. J Allergy Clin Immunol 2012;130:510-515.e1.
38. Qiu YY, Zhang XL, Qin Y, et al. Beta(2)-adrenergic receptor haplotype/polymorphisms and asthma susceptibility and clinical phenotype in a Chinese Han population. Allergy Asthma Proc 2010;31:91-7.

39. Tan S, Hall IP, Dewar J, et al. Association between beta 2-adrenoceptor polymorphism and susceptibility to bronchodilator desensitisation in moderately severe stable asthmatics. Lancet 1997;350:995-9.

40. Tantisira KG, Lake S, Silverman ES, et al. Corticosteroid pharmacogenetics: association of sequence variants in CRHR1 with improved lung function in asthmatics treated with inhaled corticosteroids. Hum Mol Genet 2004;13:1353-9.

41. Collison A, Mattes J, Plank M, et al. Inhibition of house dust mite-induced allergic airways disease by antagonism of microRNA-145 is comparable to glucocorticoid treatment. J Allergy Clin Immunol 2011;128:160-167.e4.

42. Vazquez-Tello A, Semlali A, Chakir J, et al. Induction of glucocorticoid receptor-beta expression in epithelial cells of asthmatic airways by T-helper type 17 cytokines. Clin Exp Allergy 2010;40:1312-22.

43. Rosmond R. The glucocorticoid receptor gene and its association to metabolic syndrome. Obes Res 2002;10:1078-86.

44. Panek M, Pietras T, Fabijan A, et al. Effect of glucocorticoid receptor gene polymorphisms on asthma phenotypes. Exp Ther Med 2013;5:572-80.

45. Yang N, Ray DW, Matthews LC. Current concepts in glucocorticoid resistance. Steroids 2012;77:1041-9.

46. Sun LC, Lin JT, Li W, et al. Nicotine inhibits histone deacetylase 6 activity and chaperone-dependent activation of the glucocorticoid receptor in A549 cells. Chin Med J (Engl) 2012;125:662-6.

47. Kannan Y, Wilson MS. TEC and MAPK Kinase Signa11ing Pathways in T helper (T)cell Development, T2 Differentiation and Allergic Asthma. J clin ceu Immunol 2012;suppl 12:11.

48. Li W, Lin JT, Sun LC, et al. Mechanism of p38 mitogen-activated protein kinase inhibitor SB203580 to glucocorticoid sensitivity. Zhonghua Yi Xue Za Zhi 2012;92:2570-3.

49. Hao M, Lin JT. Molecular mechanism of glucocorticoid insensitivity. Natl Med J China 2014;(26):2073-5.

50. Matsumura Y. Heterogeneity of glucocorticoid resistance in patients with bronchial asthma. Int J Biomed Sci 2010;6:158-66.

51. Axelsson M, Ekerljung L, Lundbäck B. The Significance of Asthma Follow-Up Consultations for Adherence to 
Asthma Medication, Asthma Medication Beliefs, and Asthma Control. Nurs Res Pract 2015;2015:139070.

52. D'Amato G, Vitale C, D'Amato M, et al. Thunderstormrelated asthma: what happens and why. Clin Exp Allergy 2016;46:390-6.

53. Gratziou Ch, Florou A, Ischaki E, et al. Smoking cessation effectiveness in smokers with COPD and asthma under real life conditions. Respir Med 2014;108:577-83.

54. Sheehan WJ, Phipatanakul W. Difficult-to-control asthma: epidemiology and its link with environmental factors. Curr Opin Allergy Clin Immunol 2015;15:397-401.

55. Toskala E. Work-related airway diseases. ORL Head Neck Nurs 2013;31:11-6.

56. Cowl CT. Occupational asthma: review of assessment, treatment, and compensation. Chest 2011;139:674-81.

57. Ledford DK, Wenzel SE, Lockey RF. Aspirin or other nonsteroidal inflammatory agent exacerbated asthma. J Allergy Clin Immunol Pract 2014;2:653-7.

58. Garcia-Garcia ML, Calvo RC, Del RRT. Pediatric Asthma and Viral Infection. Arch Bronconeumol 2016;52:269-73.

59. Licari A, Caimmi S, Bosa L, et al. Rhinosinusitis and asthma: a very long engagement. Int J Immunopathol Pharmacol 2014;27:499-508.

60. Jackson DJ, Gangnon RE, Evans MD, et al. Wheezing rhinovirus illnesses in early life predict asthma development in high-risk children. Am J Respir Crit Care Med 2008;178:667-72.

61. Turchiarelli V, Schinkel J, Molenkamp R, et al. Repeated virus identification in the airways of patients with mild and severe asthma during prospective follow-up. Allergy 2011;66:1099-106.

62. Moore WC, Bleecker ER, Curran-Everett D, et al. Characterization of the severe asthma phenotype by the National Heart, Lung, and Blood Institute's Severe Asthma Research Program. J Allergy Clin Immunol 2007;119:405-13.

63. ten Brinke A, Grootendorst DC, Schmidt JT, et al. Chronic sinusitis in severe asthma is related to sputum eosinophilia. J Allergy Clin Immunol 2002;109:621-6.

64. Bachert C, Zhang N. Chronic rhinosinusitis and asthma: novel understanding of the role of $\mathrm{IgE}$ 'above atopy'. J Intern Med 2012;272:133-43.

65. López-Chacón M, Mullol J, Pujols L. Clinical and biological markers of difficult-to-treat severe chronic rhinosinusitis. Curr Allergy Asthma Rep 2015;15:19.

66. Pearlman AN, Chandra RK, Chang D, et al. Relationships between severity of chronic rhinosinusitis and nasal polyposis, asthma, and atopy. Am J Rhinol Allergy
2009;23:145-8.

67. van de Loo KF, van Gelder MM, Roukema J, et al. Prenatal maternal psychological stress and childhood asthma and wheezing: a meta-analysis. Eur Respir J 2016;47:133-46.

68. Ritz T, Bobb C, Griffiths C. Predicting asthma control: the role of psychological triggers. Allergy Asthma Proc 2014;35:390-7.

69. Idrees M, FitzGerald JM. Vocal cord dysfunction in bronchial asthma. A review article. J Asthma 2015;52:327-35.

70. Xie H, Chen P. The latest study on obesity and asthma. Clin J Med Officers 2014;42:86-89.

71. Boulet LP. Asthma and obesity. Clin Exp Allergy 2013;43:8-21.

72. Raj D, Kabra SK, Lodha R, et al. Childhood obesity and risk of allergy or asthma.Immunol Allergy Clin North Am 2014;34:753-65.

73. Wang JF, Xie YP, Ma W, et al. Recent studies on relationship between obstructive sleep apnea hypopnea syndrome and bronchial asthma. J Clin Otolaryngol Neck Surg 2015:381-4.

74. Qiao YX, Xiao Y. Asthma and Obstructive Sleep Apnea. Chin Med J (Engl) 2015;128:2798-804..

75. Madama D, Silva A, Matos MJ. Overlap syndrome-Asthma and obstructive sleep apnea. Rev Port Pneumol (2006) 2016;22:6-10.

76. Skoczyński S, Semik-Orzech A, Szanecki W, et al. Perimenstrual asthma as a gynecological and pulmonological clinical problem. Adv Clin Exp Med 2014;23:665-8.

77. Graziottin A, Zanello PP. Menstruation, inflammation and comorbidities: implications for woman health. Minerva Ginecol 2015;67:21-34.

78. Bossé Y. Endocrine regulation of airway contractility is overlooked. J Endocrinol 2014;222:R61-73.

79. Sharifi A, Ansarin K. Effect of gastroesophageal reflux disease on disease severity and characteristics of lung functional changes in patients with asthma. J Cardiovasc Thorac Res 2014;6:223-8.

80. Rameschandra S, Acharya V, Kunal, et al. Prevalence and Spectrum of Gastro Esophageal Reflux Disease in Bronchial Asthma. J Clin Diagn Res 2015;9:OC11-14.

81. Moore WC, Meyers DA, Wenzel SE, et al. Identification of asthma phenotypes using cluster analysis in the Severe Asthma Research Program. Am J Respir Crit Care Med 2010;181:315-23.

82. Miranda C, Busacker A, Balzar S, et al. Distinguishing 
severe asthma phenotypes: role of age at onset and eosinophilic inflammation. J Allergy Clin Immunol 2004;113:101-8.

83. Szefler SJ, Phillips BR, Martinez FD, et al. Characterization of within-subject responses to fluticasone and montelukast in childhood asthma. J Allergy Clin Immunol 2005;115:233-42.

84. Berry M, Morgan A, Shaw DE, et al. Pathological features and inhaled corticosteroid response of eosinophilic and non-eosinophilic asthma. Thorax 2007;62:1043-9.

85. Woodruff PG, Khashayar R, Lazarus SC, et al. Relationship between airway inflammation, hyperresponsiveness, and obstruction in asthma. J Allergy Clin Immunol 2001;108:753-8.

86. Humbert M, Durham SR, Ying S, et al. IL-4 and IL-5 mRNA and protein in bronchial biopsies from patients with atopic and nonatopic asthma: evidence against "intrinsic" asthma being a distinct immunopathologic entity. Am J Respir Crit Care Med 1996;154:1497-504.

87. Humbert M, Grant JA, Taborda-Barata L, et al. Highaffinity $\mathrm{IgE}$ receptor (FcepsilonRI)-bearing cells in bronchial biopsies from atopic and nonatopic asthma. Am J Respir Crit Care Med 1996;153:1931-7.

88. Haldar P, Pavord ID, Shaw DE, et al. Cluster analysis and clinical asthma phenotypes. Am J Respir Crit Care Med 2008;178:218-24.

89. Green RH, Brightling CE, Woltmann G, et al. Analysis of induced sputum in adults with asthma: identification of subgroup with isolated sputum neutrophilia and poor response to inhaled corticosteroids. Thorax 2002;57:875-9.

90. ten Brinke A, Zwinderman AH, Sterk PJ, et al. "Refractory" eosinophilic airway inflammation in severe asthma: effect of parenteral corticosteroids. Am J Respir Crit Care Med 2004; 170:601-5.

91. Ogirala RG, Aldrich TK, Prezant DJ, et al. High-dose intramuscular triamcinolone in severe, chronic, lifethreatening asthma. N Engl J Med 1991;324:585-9.

92. Bossley CJ, Saglani S, Kavanagh C, et al. Corticosteroid responsiveness and clinical characteristics in childhood difficult asthma. Eur Respir J 2009;34:1052-9.

93. Kupczyk M, ten Brinke A, Sterk PJ, et al. Frequent exacerbators--a distinct phenotype of severe asthma. Clin Exp Allergy 2014;44:212-21.

94. McDonald VM, Gibson PG. Exacerbations of severe asthma. Clin Exp Allergy 2012;42:670-7.

95. Amelink M, de Nijs SB, Berger $M$, et al. Non-atopic males with adult onset asthma are at risk of persistent airflow limitation. Clin Exp Allergy 2012;42:769-74.
96. Baur X, Aasen TB, Burge PS, et al. The management of work-related asthma guidelines: a broader perspective. Eur Respir Rev 2012;21:125-39.

97. O'Byrne PM, Pedersen S, Lamm CJ, et al. Severe exacerbations and decline in lung function in asthma. Am J Respir Crit Care Med 2009;179:19-24.

98. Ulrik CS. Outcome of asthma: longitudinal changes in lung function. Eur Respir J 1999;13:904-18.

99. Bobolea I, Barranco P, Del PV, et al. Sputum periostin in patients with different severe asthma phenotypes. Allergy 2015;70:540-6.

100. Gibeon D, Batuwita K, Osmond M, et al. Obesityassociated severe asthma represents a distinct clinical phenotype: analysis of the British Thoracic Society Difficult Asthma Registry Patient cohort according to BMI. Chest 2013;143:406-14.

101.Aaron SD, Vandemheen KL, Boulet LP, et al. Overdiagnosis of asthma in obese and nonobese adults. CMAJ 2008;179:1121-31.

102. Robinson DS, Campbell DA, Durham SR, et al. Systematic assessment of difficult-to-treat asthma. Eur Respir J 2003;22:478-83.

103. Barranco P, Pérez-Francés C, Quirce S, et al. Consensus Document on the Diagnosis of Severe Uncontrolled Asthma. J Investig Allergol Clin Immunol 2012;22: 460-75.

104. Yang WJ, Liu CT. Factors associated with irreversible airflow limitation in asthma.Zhonghua Jie He He Hu Xi Za Zhi 2013;36:691-3.

105.Zhang L, Gang J, Zhigang C, et al. Irreversible airway obstruction assessed by high-resolution computed tomography (HRCT), exhaled nitric oxide (FENO), and biological markers in induced sputum in patients with asthma. Wien Klin Wochenschr 2014;126:515-23.

106. Gamble J, Stevenson M, Heaney LG. A study of a multilevel intervention to improve non-adherence in difficult to control asthma. Respir Med 2011;105:1308-15.

107. Chanez P, Wenzel S E, Anderson G P, et al. Severe asthma in adults: what are the important questions?. Journal of Allergy \& Clinical Immunology 2007;119:1337-48.

108. Xu Z. Pharmaceutical care in aerosol inhalation therapy. Pharm Care Res 2010;10:63-5.

109. Fink J B, Rubin B K. Problems with inhaler use: a call for improved clinician and patient education. Respir Care 2005;50:1360.

110.'Taylor DR, Bateman ED, Boulet LP, et al. A new perspective on concepts of asthma severity and control.Eur Respir J 2008;32:545-54. 
111. Chaudhuri R, Livingston E, McMahon AD, et al. Effects of smoking cessation on lung function and airway inflammation in smokers with asthma. Am J Respir Crit Care Med 2006;174:127-33.

112.Lazarus SC, Chinchilli VM, Rollings NJ, et al. Smoking affects response to inhaled corticosteroids or leukotriene receptor antagonists in asthma. Am J Respir Crit Care Med 2007;175:783-90.

113. Comhair SA, Gaston BM, Ricci KS, et al. Detrimental effects of environmental tobacco smoke in relation to asthma severity. PLoS One 2011;6:e18574.

114.Papi A, Paggiaro P, Nicolini G, et al. Beclomethasone/ formoterol vs fluticasone/salmeterol inhaled combination in moderate to severe asthma. Allergy 2007;62:1182-8.

115. Nave R. Clinical pharmacokinetic and pharmacodynamic profile of inhaled ciclesonide. Clin Pharmacokinet 2009; 48:243-52.

116. Bateman ED. Efficacy and safety of high-dose ciclesonide for the treatment of severe asthma. Expert Rev Respir Med 2013;7:339-48.

117. Mansur AH, Afridi L, Sullivan J, et al. Continuous terbutaline infusion in severe asthma in adults: a retrospective study of long-term efficacy and safety. J Asthma 2014;51:1076-82.

118. Ayres JG, Jyothish D, Ninan T. Brittle asthma. Paediatr Respir Rev 2004;5:40-4.

119. Pertseva T, Dissanayake S, Kaiser K. Superiority of fluticasone propionate/formoterol fumarate versus fluticasone propionate alone in patients with moderate-tosevere asthma: a randomised controlled trial. Curr Med Res Opin 2013;29:1357-69.

120. Corren J, Mansfield LE, Pertseva T, et al. Efficacy and safety of fluticasone/formoterol combination therapy in patients with moderate-to-severe asthma. Respir Med 2013;107:180-95.

121. Bateman ED, O'Byrne PM, Busse WW, et al. Oncedaily fluticasone furoate $(\mathrm{FF}) /$ vilanterol reduces risk of severe exacerbations in asthma versus $\mathrm{FF}$ alone. Thorax 2014;69:312-9.

122. Barnes PJ. Therapeutic approaches to asthma-chronic obstructive pulmonary disease overlap syndromes. J Allergy Clin Immunol 2015;136:531-45.

123. Kerstjens HA, Disse B, Schröder-Babo W, et al. Tiotropium improves lung function in patients with severe uncontrolled asthma: a randomized controlled trial. J Allergy Clin Immunol 2011;128:308-14.

124. Kerstjens HA, Engel M, Dahl R, et al. Tiotropium in asthma poorly controlled with standard combination therapy. N Engl J Med 2012;367:1198-207.

125. Bousquet J, Cabrera P, Berkman N, et al. The effect of treatment with omalizumab, an anti-IgE antibody, on asthma exacerbations and emergency medical visits in patients with severe persistent asthma. Allergy 2005;60:302-8.

126. Humbert M, Beasley R, Ayres J, et al. Benefits of omalizumab as add-on therapy in patients with severe persistent asthma who are inadequately controlled despite best available therapy (GINA 2002 step 4 treatment): INNOVATE. Allergy 2005;60:309-16.

127. Ortega H G, Liu M C, Pavord I D, et al. Mepolizumab treatment in patients with severe eosinophilic asthma. N Engl J Med 2014;371:1198-207.

128. Bel EH, Wenzel SE, Thompson PJ, et al. Oral glucocorticoid-sparing effect of mepolizumab in eosinophilic asthma. N Engl J Med 2014;371:1189-97.

129. Song CH, Lee JK. Lebrikizumab treatment in adults with asthma. N Engl J Med 2011;365:2433; author reply 2433-4.

130. Wenzel S, Ford L, Pearlman D, et al. Dupilumab in persistent asthma with elevated eosinophil levels. N Engl J Med 2013;368:2455-66.

131. Danek CJ, Lombard CM, Dungworth DL, et al. Reduction in airway hyperresponsiveness to methacholine by the application of RF energy in dogs. J Appl Physiol (1985) 2004;97:1946-53.

132. Brown RH, Wizeman W, Danek C, et al. Effect of bronchial thermoplasty on airway distensibility. Eur Respir J 2005;26:277-82.

133. Brown RH, Wizeman W, Danek C, et al. In vivo evaluation of the effectiveness of bronchial thermoplasty with computed tomography. J Appl Physiol (1985) 2005;98:1603-6.

134. Cox PG, Miller J, Mitzner W, et al. Radiofrequency ablation of airway smooth muscle for sustained treatment of asthma: preliminary investigations. Eur Respir J 2004;24:659-63.

135.Pretolani M, Dombret MC, Thabut G, et al. Reduction of airway smooth muscle mass by bronchial thermoplasty in patients with severe asthma. Am J Respir Crit Care Med 2014;190:1452-4.

136. Cox G, Thomson NC, Rubin AS, et al. Asthma control during the year after bronchial thermoplasty. N Engl J Med 2007;356:1327-37.

137. Thomson NC, Rubin AS, Niven RM, et al. Longterm (5 year) safety of bronchial thermoplasty: Asthma Intervention Research (AIR) trial. BMC Pulm Med 
2011;11:8.

138. Castro M, Rubin AS, Laviolette M, et al. Effectiveness and safety of bronchial thermoplasty in the treatment of severe asthma: a multicenter, randomized, double-blind, sham-controlled clinical trial. Am J Respir Crit Care Med 2010;181:116-24.

139. Castro M, Rubin A, Laviolette M, et al. Persistence of effectiveness of bronchial thermoplasty in patients with severe asthma. Ann Allergy Asthma Immunol 2011;107:65-70.

140. Stokes JR. Promising future therapies for asthma. Int Immunopharmacol 2014;23:373-7.

141. Rochat T, Chappuis-Gisin E, Ongaro G, et al. Pulmonary. High tech in pulmonary medicine: GeneXpert, coils and bronchial thermoplasty. Rev Med Suisse 2014;10:123-6.

142.Kaukel P, Herth FJ, Schuhmann M. Bronchial thermoplasty: interventional therapy in asthma. Ther Adv Respir Dis 2014;8:22-9.

143. Sumino K, Castro M. Bronchial thermoplasty: safe for our severe asthma patients? Ann Allergy Asthma Immunol 2013;111:311-2.

144.Keglowich LF, Borger P. The Three A's in Asthma - Airway Smooth Muscle, Airway Remodeling \& Angiogenesis. Open Respir Med J 2015;9:70-80.

145.Cox G, Miller JD, McWilliams A, et al. Bronchial thermoplasty for asthma. Am J Respir Crit Care Med 2006;173:965-9.

146. Pavord ID, Cox G, Thomson NC, et al. Safety and efficacy of bronchial thermoplasty in symptomatic, severe asthma. Am J Respir Crit Care Med 2007;176:1185-91.

Cite this article as: Lin J, Yang D, Huang M, Zhang Y, Chen P, Cai S, Liu C, Wu C, Yin K, Wang C, Zhou X, Su N; on behalf of Asthma Workgroup of Chinese Thoracic Society, Chinese Medical Association, and China Asthma Alliance. Chinese expert consensus on diagnosis and management of severe asthma. J Thorac Dis 2018;10(12):7020-7044. doi: 10.21037/ jtd.2018.11.135
147. Nong Y, Lin JT, Su N, et al. Analysis of short-term respiratory adverse events in 183 bronchial thermoplasty procedures.Zhonghua Jie He He Hu Xi Za Zhi 2017;40:176-81.

148. Dombret MC, Alagha K, Boulet LP, et al. Bronchial thermoplasty: a new therapeutic option for the treatment of severe, uncontrolled asthma in adults. Eur Respir Rev 2014;23:510-8.

149. Pavord ID, Thomson NC, Niven RM, et al. Safety of bronchial thermoplasty in patients with severe refractory asthma. Ann Allergy Asthma Immunol 2013;111:402-7.

150. Wechsler ME, Laviolette M, Rubin AS, et al. Bronchial thermoplasty: Long-term safety and effectiveness in patients with severe persistent asthma. J Allergy Clin Immunol 2013;132:1295-302.

151.Su N. Perioperative management of bronchial thermoplasty for asthma. Zhonghua Jie He He Hu Xi Za Zhi 2015;38:883-5.

152.Lin J, Nong Y, Yang D, et al. Chinese consensus statement on standard procedure and perioperative management of bronchial thermoplasty. J Thorac Dis 2017;9:5507-14.

153. Nong Y, Su N, Lin J, et al. Effectiveness and safety of bronchial thermoplasty in patients with severe asthma. Zhonghua Jie He He Hu Xi Za Zhi 2016;39:177-82.

154.Zhang Q, Zhang X, Xie J, et al. Bronchial thermoplasty in the treatment of severe asthma. Zhonghua Jie He He Hu Xi Za Zhi 2016;39:183-8.

155.Lin J, Qiu R. Pay attention to study on the appropriate populations and mechanism of bronchial thermoplasty. Zhonghua Jie He He Hu Xi Za Zhi 2016;39:161-3. 